\title{
Electrochemical Methods for the Study of Liquid Metals: Highlights from Metallurgical Transactions
}

\begin{abstract}
ANTOINE ALLANORE
Metallurgical Transactions - and its subsequent MMTA and MMTB - has been a home for numerous contributions related to electrochemistry as it applies to solid, but also liquid materials. Herein, a perspective is presented to highlight the utility of electrochemical methods as applied to the study of liquid metals. The review of a subset of papers shows the diversity of experimental options available to investigate the thermodynamic properties of liquid metals, as well as certain limitations. A specific set of results covering the entire range of two liquid binary systems is reviewed as an illustration of the static electrochemical potential difference method. More recent developments offered by dynamic electrochemical potential methods, using direct and alternating currents or containerless configurations, are reviewed. Advances in electrochemical studies of liquid metals bring the prospect of simultaneous thermodynamic and transport properties measurements closer to reality.
\end{abstract}

https://doi.org/10.1007/s11663-021-02278-4

(C) The Minerals, Metals \& Materials Society and ASM International 2021

\section{INTRODUCTION}

ELECTROCHEMICAL measurements are essential in high temperature materials extraction and manufacturing processes. Familiar examples encompass oxygen sensors for liquid iron or cell voltage in aluminium electrolysis. Electrochemical insights into liquid metal systems are somehow less popular in mainstream metallurgy research despite this industrial reality. Interestingly, new electrically driven processes, sensors, or power devices, e.g., liquid metal batteries, ${ }^{[1]}$ have often been conceived from experimental insights gained with electrochemical methods.

The majority of materials processes involve melts, where one metal is typically a major constituent, analogous to a solvent. In terms of yearly tonnage of structural materials, iron is the world leading solvent, but aluminium, nickel or titanium are not to be forgotten. Additional elements, often metals, are added to the solvent in low concentration (solutes, typically percent or fraction of a percent). The end-goal of processing is then the formation upon solidification of multiple phases, herein in the sense of Gibbs, with targeted spatial distribution, both at the macro- and micro-scale. Along the way, undesirable solutes such as

ANTOINE ALLANORE is with the Department of Materials Science and Engineering, Massachusetts Institute of Technology, 77 Massachusetts Avenue, Cambridge MA 02139. Contact e-mail: allanore@mit.edu

Manuscript submitted January 28, 2021; accepted July 9, 2021

Article published online October 8, 2021. dissolved gas and impurities from the solvent or the solute feedstocks are also present, contributing to additional chemical reactions in the melt and during solidification. When it comes to casting, the phase distribution and the composition of the different "assolidified" phases dictate the performances of downstream processes (e.g., heat treatment, rolling) in controlling minor-elements distribution and ultimately macro- and micro-structures of semi-finished stocks.

This summary explains the importance of process metallurgy models, which call upon thermodynamic and transport properties of melts. Nowadays thermodynamic models for process metallurgy are often judged from their ability to predict phase boundaries, i.e., phase equilibria (e.g., CALculation of PHase Diagram, CALPHAD).

Fundamentally, one aims for the function $G\left(x_{i}, x_{j}, x_{k}, \ldots\right)$, where $x_{i}, x_{j}, x_{k}, \ldots$ identify the concentration of the elemental species, and it is the variation of $\mathrm{G}$ as a function of temperature that is at play for a melt process at constant pressure. $G$ is the Legendre transform of the energy (or chemical work), to distinguish other available forms of energy transfer:

$$
G=(U+P V)-T S=H-T S
$$

Enthalpy, defined $H=U+P V$ to include hydrostatic work, evaluates the equivalent heat $(\delta Q)$ for a transformation at constant pressure, from $(\mathrm{d} H)_{P}=(\delta Q)_{P}$. It is enthalpy which provided the earliest access to thermodynamics of materials, as measureable in calorimeters, commonly used to inform phase transformation energetics. Some advances in calorimetry for high temperature have been reviewed elsewhere ${ }^{[2-4]}$ to evaluate 
formation or solution enthalpies. ${ }^{[5,6]}$ Energies - enthalpy included - do not have a universal physical origin, and an arbitrary value of 0 is assigned for the enthalpy of elements in their standard state.* The vari-

${ }^{*}$ See Lupis $^{[7]}$ for thermodynamic definitions, notations and derivations.

ation of enthalpy with temperature is described by the heat capacity at constant pressure, also measurable in calorimeters: $C_{P}=\left(\frac{\mathrm{d} H}{\mathrm{~d} T}\right)_{P}$.

The influence of temperature on the Gibbs energy of a phase, as used in mixing theory is fundamentally described by its entropy, $S$,

$$
S=-\left(\frac{\partial G}{\partial T}\right)_{P}=\frac{1}{T}\left(\frac{\partial C_{P}}{\partial T}\right) .
$$

In striking contrast to energy, the second and third laws of thermodynamics set the origin and direction of change for entropy. An element in its stable phase at equilibrium at a temperature of $0 \mathrm{~K}$ has a molar entropy of $0 \mathrm{~J} / \mathrm{mol} / \mathrm{K}$. This combined with the 2 nd law incidently sets the variation of $C_{P}$ with temperature toward $0 \mathrm{~K}$, and ultimately $\mathrm{G}$ for a given phase in a given state (e.g liquid) can be expressed as a sole function of entropy and temperature. In principle, being able to express the temperature dependence of $\mathrm{G}$ for all possible phases for a given number of constitutive elements is sufficient to determine the phase(s) with the lowest Gibbs energy. This enables, via numerical optimization, the identification of the equilibrium phases and their relative abundance at a given temperature.

The recent advances in computational power and prediction capacity for some of those properties are reviewed below, to highlight the importance and possible advances that electrochemical methods can provide:

1. Ab-initio calculations are very useful at $0 \mathrm{~K}$, informed from quantum-mechanics, to set the grounds for energetics. In principle the energy states that are possible when allowing bonding between elements can be computed and compared, informing Eq. [1] without thermal effects.

2. The entropy of metals at any temperature and in any state of matter remains a frontier. Recent emphasis on experimental methods that are based on phonons and vibration modes have been put forth ${ }^{[8]}$ to support models derived from wave mechanics and periodicity. The actual entropy of melts and liquid metals remains poorly described and understood.

3. The concept of a mixed state (i.e., a solution) is anchored on atomistic or geometric descriptions, supported by long-range order such as found in crystals. Mid- and short- range ordering then calls for high-energy experiments (e.g., neutron diffraction) and numerical fitting of distribution functions to atom-based solution models. This makes understanding the role of bonding electrons difficult, despite phenomenological attempts based on electronegativity. ${ }^{[9,10]}$ No computational methods are satisfactory yet to predict the electronic properties of liquids.

4. In actual materials processing, multiple components are present and exposed to gradients of composition and of temperature in condensed matter, as well as in the gas phase. This not only calls for precise thermodynamic models, in particular with accurate temperature dependence and entropy, but also insights into properties that affect transport and reactivity such as viscosity, diffusivity or electrical (ionic and electronic) conductivity.

There remains a need for experimental insights to probe liquid systems, in particular methods that do not require high-energy particles or fit to a-priori structural models. Herein we review how methods based on electrochemical potential differences (formerly known as the electromotive force measurement, $E M F$ method) can determine the Gibbs energy of melts in the context of metallurgy.

Several prior reviews are available in this journal on some materials advances, such as by Pratt ${ }^{[11]}$ and more recently by Fray, ${ }^{[12]}$ which both focused on solid electrolytes. An overview discussing the importance of the electrochemical method for CALPHAD modeling has been published in $2010,{ }^{[13]}$ again focusing on electrolyte materials chemistry and with minimal insights on solution thermodynamics or electrochemistry. Several references provide detailed experimental insights, in particular the proceedings of the conference from 1968 entitled Electromotive Force Measurements in High Temperature Systems, ${ }^{[14]}$ though with limited insight into liquid metals.

In the context of the half-century of existence of Metallurgical Transactions, most of the papers cited and used to inform this work are selected from that journal. This means many pioneering works published before the journal creation (e.g., Transactions of AIME) are not included, despite their key importance in particular for iron and steel metallurgy. Using Springer's search engine in 2020 with the keyword "electrolyte" returns around 1060 references. A search with the keyword "electromotive force" or "EMF" returns 429 entries. The present review is limited to a subset from around 1500 papers from the journal, in particular from those with experimental results on liquid metals.

Section II presents first the fundamental electrochemistry discussing the relevant thermodynamic settings. Second, a subset of results is discussed with respect to the various solution thermodynamic settings that have been investigated with liquid metals. This enables one to propose a classification of the prior results and highlights similarities and challenges of the methods.

Section III discusses in greater details the static, conventional electrochemical potential difference method, using two papers that investigated the entire binary compositions of liquid alloys. Those provide illustration of the results from such method, and their presentation. Section IV discusses results obtained with dynamic electrochemical methods, with direct or 
alternating currents, as possible advances that can ultimately couple transport properties with thermodynamic measurements.

It is the author's hope that such review will inspire researchers to pursue melts measurements using electrochemistry. The review shows that the electrochemical method has provided essential data for metallurgical processing and is essential to deliver insights into entropy as well as transport properties.

\section{BACKGROUND}

This section provides first (II-A) the essential fundamentals that support the use of electrochemical potential control and measurements to inform the Gibbs energy of materials, in particular in the context of liquid metal solutions. Section II-B is a review of a subset of publications from Metallurgical Transactions dedicated to the electrochemical potential difference measurements, to highlight key experimental advances, findings and outcome.

\section{A. Fundamentals}

The schematic experimental configuration supporting electrochemical method application to liquid metal is presented in Figure 1. It is an electrochemical cell, the basis of power generation (battery, fuel cell) or electrolysis technologies. Electrochemical equilibrium between the two different electrodes, themselves in internal thermodynamic equilibrium, generates an electrical potential difference $\Delta E$ (a voltage) which can be used for electrical work in an external circuit. If doing so, a net current is generated, as indicated by the electron flow, the direction of which is determined by the chemical nature of the electrode materials.

Often the cell is placed in isothermal conditions as provided by a furnace, and in an isobaric environment as provided by a chamber with controlled atmosphere. Essential to the precision of the data, the thermal stability of the cell needs attention. With modern electronic temperature controllers and standardized and calibrated thermocouples, a stability and accuracy ranging from a fraction to few degrees can be obtained for temperature up to $1600{ }^{\circ} \mathrm{C}$.

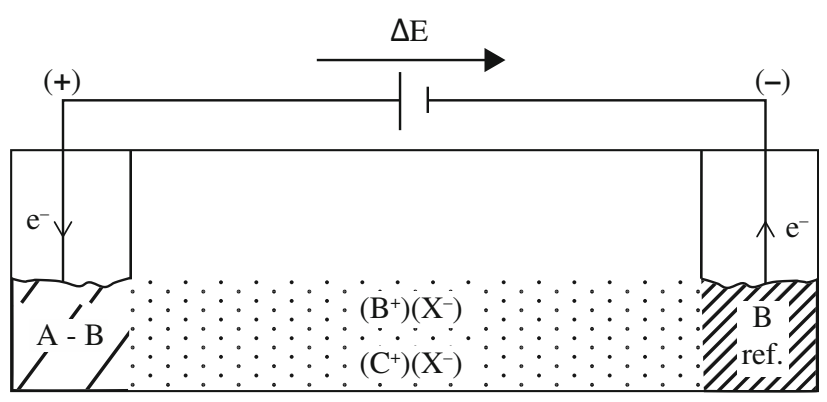

Fig. 1-Schematic electrochemical cell for the investigation of the binary system $\mathrm{A}_{1-x}-\mathrm{B}_{x}$.
Less accuracy is expected above this temperature $(10 \mathrm{~K}$ to $50 \mathrm{~K})$ due to the lack of standardized thermocouples, though the thermal stability can reach a similar range as found below $1600{ }^{\circ} \mathrm{C}$.

The electrical measurements are conducted with high-precision devices of high electrical impedance (several $M \Omega$ ). A potentiostat can provide a resolution and an accuracy for the voltage of few microvolt $\left(10^{-6} \mathrm{~V}\right)$. The minimum current range can be of few nanoamperes $\left(\sim 10^{-9} \mathrm{~A}\right)$, with a precision of a percent of picoampere $\left(\sim 10^{-15} \mathrm{~A}\right)$.

The electrode material connected to the positive terminal in Figure 1 and labeled $\mathrm{A}-\mathrm{B}$ is the liquid alloy under investigation, here a binary mixture of A and B. Its composition, $x$, is often prescribed, and known with the accuracy of weight measurement methods if both species are condensed (solid, liquid) in their standard state. ${ }^{* *}$ The

**A thermodynamic definition; the most stable form of $\mathrm{A}$ and $\mathrm{B}$ at a given temperature and for one atmosphere of pressure.

precision may be different if one component standard state is gaseous (e.g., hydrogen $\mathrm{H}$, oxygen $\mathrm{O}$ ), as defined by the chosen method to control and analyze the gas phase composition as well as the rate of solubilization of gases in the metal. The chemical potential $\mu_{i}$ (or partial molar Gibbs energy) is the targeted material property, in particular its variation with temperature and composition, i.e., $\mu_{i}(T, x)$. The electrochemical equilibrium is achieved with the transfer of charged species via the electrolyte between both electrodes, i.e., to or from a second electrode of known thermodynamic state, named a reference electrode in Figure 1 . For simplicity here we assume the cation $\mathrm{B}^{+}$ is transferred and the reference electrode is pure $\mathrm{B}$ $\left(x_{\mathrm{B}}^{\text {ref. }}=1, \quad \mu_{\mathrm{B}}^{\text {ref. }}=\mu_{\mathrm{B}}^{\circ}\right)$. The corresponding chemical potential gradient $\Delta \mu_{\mathrm{B}}$ is

$$
\Delta \mu_{\mathrm{B}}=\mu_{\mathrm{B}}-\mu_{\mathrm{B}}^{\mathrm{ref}}
$$

The transfer is possible thanks to the electrolyte, which chemically and electronically separates the two electrodes. ${ }^{\dagger}$ The electrolyte enables electrochemical equilib-

${ }^{\dagger}$ Mix electronic and ionic conduction is also in principle possible, though not commonly used.

rium via ionic conductivity and transport of a species undergoing chemical equilibria with the electrodes, here $\mathrm{B}^{+}$. The actual cell voltage $E_{\text {cell }}=\Delta E$ is obtained from the number of exchanged electrons per mole of $\mathrm{B}\left(n_{\mathrm{e}}\right.$, unity for monovalent $\left.\mathrm{B}^{+}\right)$, the chemical potentials of the electron $\left(\mu_{\mathrm{e}^{-}}\right)$and the Faraday constant $(F)$

$$
E_{\text {cell }}=\frac{1}{n_{\mathrm{e}} F}\left(\mu_{\mathrm{e}^{-}}^{(+)}-\mu_{\mathrm{e}^{-}}^{\text {ref. }}\right)
$$

The corresponding electrochemical reactions at the reference and at the binary mixture are: 


$$
\begin{gathered}
\mathrm{B}^{\text {ref. }} \rightarrow \mathrm{B}^{+}+\mathrm{e}^{-} \\
\mathrm{B}^{+}+\mathrm{e}^{-} \rightarrow \mathrm{B}
\end{gathered}
$$

and internal equilibrium in each electrodes yields

${ }^{\ddagger}$ Here the junction potentials neglected, see Reference 14 for more on this matter.

$$
\begin{gathered}
\mu_{\mathrm{B}}^{\text {ref. }}=\mu_{\mathrm{e}^{-}}^{\text {ref. }}+\mu_{\mathrm{B}}^{+} \\
\mu_{\mathrm{B}}=\mu_{\mathrm{e}^{-}}^{(+)}+\mu_{\mathrm{B}}^{+}
\end{gathered}
$$

which combined with Eq. [4] provide the difference of chemical potential $\Delta \mu_{\mathrm{B}}$ from the experimentally measured cell potential difference:

$$
\Delta \mu_{\mathrm{B}}=\left(\mu_{\mathrm{B}}-\mu_{\mathrm{B}}^{\text {ref. }}\right)=-F \times E_{\text {cell }}
$$

The difference of chemical potential $\Delta \mu_{\mathrm{B}}$ is a partial molar property, $G_{\mathrm{B}}^{\mathrm{M}}$, i.e., a property of $\mathrm{B}$ in solution with A. $\Delta \mu_{\mathrm{B}}$ can be expressed according to any chosen solution thermodynamic formalism. Often in chemical metallurgy one introduces the activity function $a_{\mathrm{B}}\left(T, x_{\mathrm{B}}\right)$, itself sometimes expressed as the product of an activity coefficient $\gamma_{\mathrm{B}}\left(T, x_{\mathrm{B}}\right)$ and the concentration $x_{\mathrm{B}}$. Equation [9] is then a direct measurement of the functions of a given solution model, for example if one adopts a Raoultian reference state

$$
\Delta \mu_{\mathrm{B}}=G_{\mathrm{B}}^{\mathrm{M}}=R T \ln a_{\mathrm{B}}=R T \ln \left(\gamma_{\mathrm{B}} x_{\mathrm{B}}\right)=-F \times E_{\text {cell }}(T)
$$

The choice of a Raoultian thermodynamic reference state for the solution is convenient for the chosen example, i.e., when $\left(a_{\mathrm{B}}\right)_{x_{\mathrm{B}} \rightarrow 1} \rightarrow 1, \mu_{\mathrm{B}^{\text {ref. }}}=\mu_{\mathrm{B}}^{\circ}$ which corresponds to the actual physical state of the reference electrode. Measurements of the cell voltage at various values of temperature and $\mathrm{B}$ content $\left(x_{\mathrm{B}}\right)$ lead to the entire suite of thermodynamic properties of $\mathrm{B}$ in the A-B solution of study. The integration of the GibbsDuhem equation (see Reference 7):

$$
x_{\mathrm{A}} d \ln \mu_{\mathrm{A}}+x_{\mathrm{B}} d \ln \mu_{\mathrm{B}}=0
$$

either graphically ${ }^{[15]}$ or analytically provides the thermodynamic properties of the other components (here A).

The partial molar Gibbs energy from Eq. [10] can be expressed as a function of a combination of enthalpic and entropic contributions:

$$
G_{\mathrm{B}}^{\mathrm{M}}=H_{\mathrm{B}}^{\mathrm{M}}-T S_{\mathrm{B}}^{\mathrm{M}}
$$

informing both the energetic and entropic fundamentals of the solution.
Departure from ideal behavior $\left(\gamma_{\mathrm{B}} \neq 1\right)$ can be represented via the excess partial molar enthalpy $\left(H_{\mathrm{B}}^{\mathrm{E}}\right)$ and entropy $\left(S_{\mathrm{B}}^{\mathrm{E}}\right)$ :

$$
\begin{aligned}
H_{\mathrm{B}}^{\mathrm{E}} & =H_{\mathrm{B}}^{\mathrm{M}}=\left(\frac{\partial G_{\mathrm{B}}^{\mathrm{M}} / T}{\partial 1 / T}\right)_{\mathrm{P}} \\
& =-F T^{2}\left(\frac{\partial E_{\mathrm{cell}}(T) / T}{\partial T}\right)=R\left(\frac{\partial \ln \gamma_{\mathrm{B}}}{\partial 1 / T}\right)_{\mathrm{P}}
\end{aligned}
$$

$$
\begin{aligned}
S_{\mathrm{B}}^{\mathrm{E}} & =S_{\mathrm{B}}^{\mathrm{M}}-S_{\mathrm{B}}^{\mathrm{M}(\mathrm{id})}=\left(\frac{\partial G_{\mathrm{B}}^{\mathrm{M}}}{\partial T}\right)+R \ln x_{\mathrm{B}} \\
& =F\left(\frac{\partial E_{\mathrm{Cell}}(T)}{\partial T}\right)+R \ln x_{\mathrm{B}} \\
& =-R \ln \gamma_{\mathrm{B}}-R T\left(\frac{\mathrm{d} \ln \gamma_{\mathrm{B}}}{\mathrm{d} T}\right)+R \ln x_{\mathrm{B}}
\end{aligned}
$$

From Eqs. [13a] and [13b], it is clear that the electrochemical method provides in principle a direct measurement of all the thermodynamic properties of mixing of the binary A-B. An extensive range of temperature of operation can therefore probe all the features of the materials system, including boundaries for liquid-solid equilibria (liquidus) or miscibility gaps. The isothermal investigation of the entire range of composition of $\mathrm{B}$ can inform the chemical potential across the stability range for the liquid A-B. From Gibbs-Duhem (Eq. [11]), this then provides the solution thermodynamics of all the other components in solution, which for multicomponent systems can prove particularly difficult to access otherwise.

The quest for a large range of temperature and composition can extend the utility of the electrochemical method for thermodynamics. Hereafter we review some of the contributions found in Metallurgical Transactions.

\section{B. Survey of Contributions from Metallurgical Transactions}

Acknowledging that electrochemical transport and equilibrium can be achieved in a variety of media may suggest a variety of electrolytes. However, chemical compatibility with the liquid $\mathrm{A}-\mathrm{B}$, the chosen atmosphere (reducing, oxidizing, inert) and the temperature range of study promptly limit the electrolyte choice. One can distinguish solid vs molten electrolyte cells. Solid electrolytes are traditionally studied and developed in the field of ceramics, while molten electrolytes traditionally pertain to the field of chemical metallurgy. Nowadays both fields are experiencing a renewed interest in the context of power generation (batteries), electronics (electroceramics) or electricity-driven materials processing (electrometallurgy).

Even limiting ourselves to the liquid phase of $\mathrm{A}-\mathrm{B}, \mathrm{A}$ and B can be of very diverse chemical nature. Often A is considered the solvent [main solvents in metallurgy are iron $(\mathrm{Fe})$, copper $(\mathrm{Cu})$ and aluminium $(\mathrm{Al})]$, in which the behavior of solutes B is investigated. Manganese (Mn) is a common solute for those solvents, as low as few 
percent in $\mathrm{Al}$, or as high as several ten percent in $\mathrm{Fe}$ or $\mathrm{Cu}$ master alloys. The solute $\mathrm{B}$ can be a gas, such as $\mathrm{O}$ and $\mathrm{S}$ in $\mathrm{Fe}$ and $\mathrm{Cu}$ or $\mathrm{H}$ for $\mathrm{Al}$, traditionally considered less soluble. ${ }^{\S}$ The thermodynamic formalism presented

\footnotetext{
${ }^{\S}$ Determining if a solute is dilute or concentrated remains empirical No satisfactory theoretical definition have been found in particular if solid-state solution behavior is used as a guideline. Insights from entropy differences between a gas solute in a solid or in a liquid metal illustrate well the advantages and limitations of available theoretical solution models. ${ }^{[16]}$
}

above is applicable to any liquid solution behavior, including as it evolves with temperature. However, we herein propose to sort solutions into 4 categories; dilute (e.g., $\mathrm{O}$ in $\mathrm{Fe}$ at $1600{ }^{\circ} \mathrm{C},{ }^{[17]}$ ) fully miscible (e.g., $\mathrm{Al}$ in $\mathrm{Cu}^{[18]}$ ), phase separating (e.g., $\mathrm{S}$ in $\mathrm{Cu}^{[19]}$ ) or reacting (e.g., yttrium $(\mathrm{Y})$ in $\mathrm{Al}$ saturated with alumina $\left(\mathrm{Al}_{2} \mathrm{O}_{3}\right)^{[20]}$. Independently, we sort experimental methods according to the standard state of the solute $\mathrm{B}$; gaseous (G), liquid (L) or solid (s). From the surveyed contributions to MMT that explicitly refer to the electrochemical method, more than 150 papers were found to provide sufficient insights into thermodynamics of mixing of metal-based liquids. The papers that explicitly provide and discuss experimental data informing the solution behavior using the electrochemical method have been analyzed. Some of their main features are summarized in Table 1 and discussed hereafter.

\section{Solid-state electrolytes}

Table I illustrates that solid electrolytes have primarily been used for a solute B that is gaseous. For liquid metals, this often corresponds to B being dilute. As with most solid electrolyte development, it is the quest for in-situ sensing of dissolved species in industrial casting or liquid metal processes that motivates those developments, as reviewed previously, ${ }^{[55]}$ including in this journal, ${ }^{[12]}$ and recently ${ }^{[13]}$. Most of the studies surveyed herein study oxygen as solute. This supports the chosen chemical nature of the electrolyte, most often zirconia $\left(\mathrm{ZrO}_{2}\right)$-based, with addition of calcia $(\mathrm{CaO})$, magnesia $(\mathrm{MgO})$ or yttria $\left(\mathrm{Y}_{2} \mathrm{O}_{3}\right)$. Success with thoria-based electrolytes $\left(\mathrm{ThO}_{2}\right)^{[17,56]}$ and magnesia-based $\mathrm{MgO}^{[25,52]}$ have also been found. This is a situation where $\mathrm{O}$ is the solute, and $\mathrm{O}^{2-}$ is the species at equilibrium at each electrode. This means $\mathrm{B}$ is in equilibrium as an anion $\mathrm{B}^{2-}$. The reference electrode material is often a chemical mixture $\mathrm{MB} / \mathrm{M}$ at equilibrium at a fixed $B_{2}$ partial pressure where $M$ is a metal and $\mathrm{MB}$ is a stable metal compound at the operating pressure and temperature. Examples include $\mathrm{Mo} / \mathrm{MoO}_{2}$ or $\mathrm{Cr} / \mathrm{Cr}_{2} \mathrm{O}_{3} \cdot{ }^{\left[{ }^{[5]}\right.}$ Additional chemical thermodynamic information is then needed to quantify the mixing behavior of $\mathrm{O}$, and verifying the achievement of reproducible equilibria across the cell is necessary.

Solid-oxides chemical and transport properties fix an operational range for the equivalent partial pressure of oxygen between $10^{-30}$ and $10^{-19}$ at around $1200 \mathrm{~K} .^{[11]}$ This is still high for many metals, in particular $\mathrm{Al}$, Ti, or rare-earth. Of note, the temperature range and partial pressure tolerated by the electrolyte fix the maximum oxygen content that can be studied, which for the studies in Table I is around $5000 \mathrm{ppm}$.

The addition of a molten or solid compound in equilibrium and contact with the A-B system and the solid-oxide electrolyte can extend the range of concentration of B. It also enables the investigation of B when its standard state is solid. In that situation the experimental situation is more challenging, and several ancillary thermodynamic and kinetic data about each reaction are necessary to enable analysis of the measurements with the solid electrolyte. In particular, the chemical and the electrical compatibility between the solid electrolyte and the additional compounds needs to be established.

The lowest temperature of operation is the one necessary to overcome the relatively slow transport in the electrolyte, and reach equilibrium. The maximum temperature of operation is high, though the lifetime of the cell is then limited by chemical reaction with the liquid metal. One study used zirconia-based electrolyte to investigate $\mathrm{P},{ }^{[32]}$ though with challenges due to the high vapor pressure of this solute. Alternative solid electrolytes include fluorides, mostly calcium fluoride commonly used for very reactive metals ${ }^{[20,58]}$ and recently revisited for $\mathrm{Ca},{ }^{[59]} \mathrm{Ba},{ }^{[60]}$ or $\mathrm{Sr}^{[61]}$ ). Stability issues for those metals in high concentration and at high temperature make measurements far from the liquidus challenging. Details about the underlying method have been recently made available online. ${ }^{[62]}$

The development of a suite of $\beta$-alumina $\left(\mathrm{Al}_{2} \mathrm{O}_{3}\right)$ electrolytes has enabled the study of equilibria involving sodium $(\mathrm{Na})$, and offered a new way to investigate solute elements in a solid standard state using a solid electrolyte. Application of such electrolytes to measure $\mathrm{S}$ or even $\mathrm{N}$ in liquid metals has also been put forth. In such conditions the mobile species in the electrolyte is not directly the one undergoing electrochemical equilibrium in the metal. Instead, the species of interest, say $\mathrm{S}$ in the liquid metal, undergo a spontaneous chemical reaction (e.g., formation of a sulfide ${ }^{[35]}$ ) in contact with the alkaline-earth $\beta$-alumina (there $\mathrm{Sr}$ ). This fixes the chemical potential of $\mathrm{S}^{2-}$ in the membrane, which is itself probed with another equilibrium $\mathrm{MS} / \mathrm{M}$ at fix pressure. This is somehow analogous to the MB/M equilibria for oxygen but this time on the A-B side of the solid electrolyte. Also, the species B now undergoes spontaneous reaction within the metal solvent. A recent work ${ }^{[63]}$ proposed to use calcium aluminate instead of $\beta$-alumina, using the oxygen concentration at equilibrium with the oxide membrane after the equilibrium reaction of $\mathrm{Ca}^{2+}$ with $\mathrm{S}$ to form CaS. Superprotonic membranes (for example $\mathrm{CaZrO}_{3}$, codoped with $\mathrm{Al}_{2} \mathrm{O}_{3}$ and $\operatorname{In}_{2} \mathrm{O}_{3}$ ), i.e., that enable transport of the proton, have been put forth to probe the hydrogen $(\mathrm{H})$ content in copper ${ }^{[33,64]}$ or aluminium. ${ }^{[65]}$ A comprehensive evaluation of the range of temperature, of the compatible alloying elements and of $\mathrm{H}$ concentration compatible with such approaches would be beneficial to establish how those can inform complete solution model. 


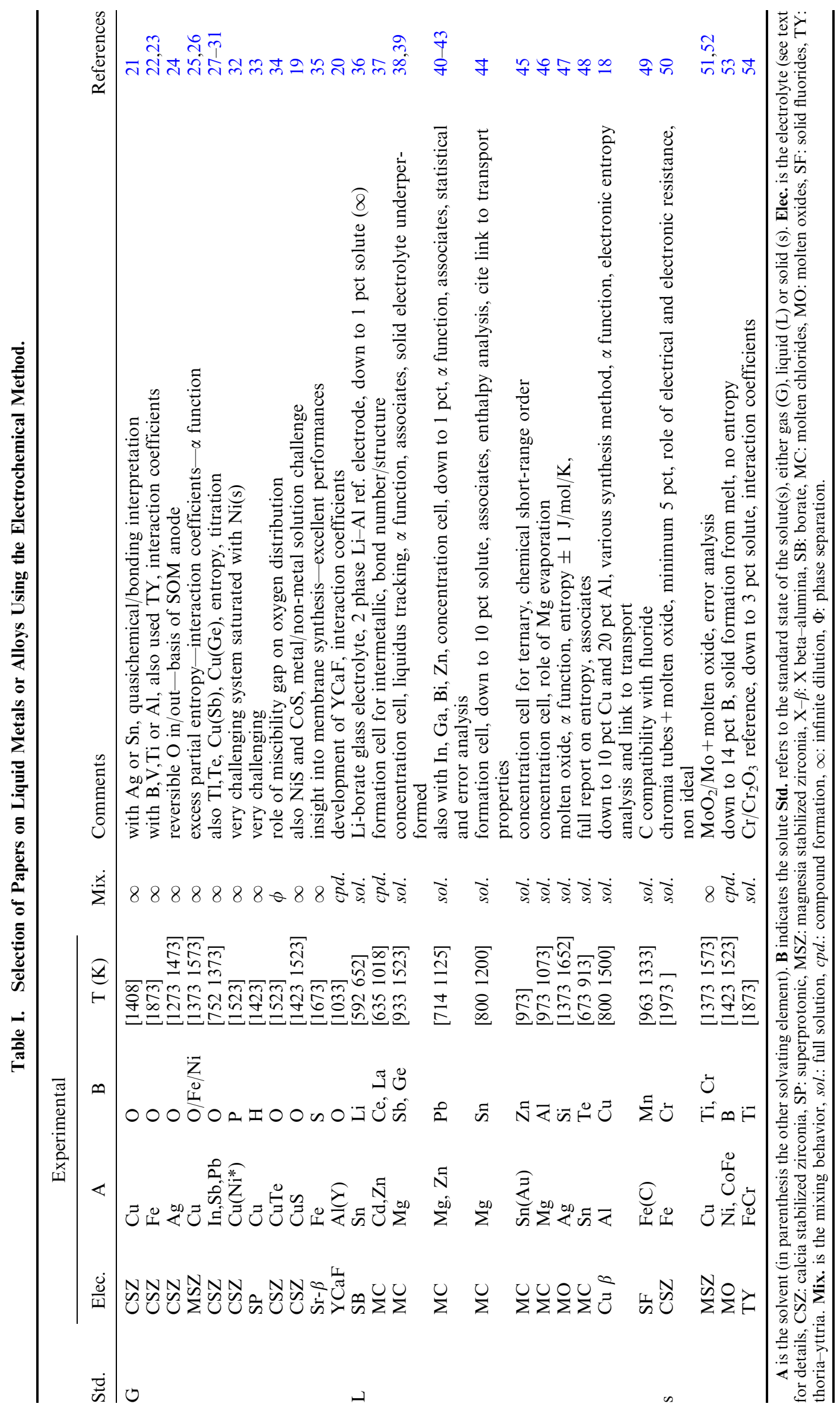




\section{Molten electrolytes}

The most common electrolyte for the electrochemical method when the solute standard state is liquid is a molten electrolyte. Molten chlorides are routinely used, in particular for medium temperatures $(592 \mathrm{~K}$ to $1652 \mathrm{~K}$ in the surveyed studies) and consequently for low-melting metals. The most typical set-up is a concentration cell, i.e., where $\mathrm{B}$ is present in both electrodes at a known concentration, as illustrated in Figure 1. Reaction (or formation) cells have been used, where the electrolyte is actively decomposed to force B production at one electrode and the second electrode is typically evolving gas. In this case, the knowledge of the electrolyte solution thermodynamics, more precisely its decomposition voltage, is necessary (see dedicated section hereafter). Metals used in electronics $(\mathrm{Pb}, \mathrm{Sn}$, $\mathrm{Bi}, \mathrm{Ga}, \mathrm{In}$ ) and their mixtures with $\mathrm{Ge}$ or Te have been investigated extensively using molten chloride electrolytes. Molten halides supported the few studies where the entire range of composition of the liquid binary is probed, over a quite extensive range of temperature. Such studies have turned up evidence of a chemical structure in liquid metal solutions that evolves with temperature, i.e., departure from ideal mixing or regular solutions, are found. It revealed that even such simple systems as metal binaries can exhibit complex physical-chemical interactions that escape traditional solution thermodynamic models. Experimental results ${ }^{[38,40,42]}$ supported the development of the thermodynamic model of associates, and offered an opportunity to discuss links with transport properties such as electrical conductivities. Molten electrolytes are not limited to molten halides. One example is molten oxides, e.g., using molten silicate for the study of the $\mathrm{Ag}-\mathrm{Si}$ system. ${ }^{[47]}$

Solid electrolytes can also handle $\mathrm{B}$ in a liquid standard state in solution in a liquid metal A, though the papers surveyed herein indicate that it is rare to investigate the entire composition range. One recent report using $\mathrm{Cu}-\beta$ alumina $\left(\mathrm{Al}_{2} \mathrm{O}_{3}\right)^{[18]}$ provided the first data across the entire liquid system $\mathrm{Al}-\mathrm{Cu}$, using a copper reference electrode. Borate electrolytes to study boron seem to be an exception, because molten borates are both not too reactive and compatible with several metals.

\section{Entropy and solution behavior}

While all those reports have calculated Gibbs energy from the measured electrical signals, very few have actually investigated an extensive range of composition and temperature. This is partly due to the limitations of the experimental apparatus. It is also because liquid metal solution models rarely have an explicit temperature dependence of the enthalpy and entropy. Often too, only relatively narrow ranges of composition and temperature are investigated, due to a focus on the current industrial processes which have rather narrow specifications. Nevertheless, some papers, as indicated in the comment section of Table I, provided thorough insights into the full mixing behavior of the investigated solutions, and therefore do support entropy evaluation. Unfortunately, statistical information is rarely provided concerning the stability and accuracy of the electrical and temperature signals, which are the essential signals to confidently inform entropy.

With the interest to foster the links between thermodynamic solution models and the electrochemical method for liquid metals, we review in Section III some important aspects of the most common method, the Static Electrochemical Potential Difference Method, pertinent when the entire composition range is liquid. This corresponds to a standard state for A and B that is a liquid metal ${ }^{[6] \S \S}$ and as such, molten electrolyte will be

\footnotetext{
${ }^{\$}$ note that this is technically not the case for sulfides (A-S), selenides (A-Se) and tellurides (A-Te) where B is not a metal and for which liquid solutions often exhibit semiconducting behavior. ${ }^{[66,67]}$
}

used as an illustrative example.

\section{STATIC ELECTROCHEMICAL POTENTIAL MEASUREMENT METHOD}

Two contributions to MMTB, one on tin (Sn)-tellurium (Te) by Rakotomavo et al. ${ }^{[68]}$ and one on tin (Sn)-bismuth (Bi) by Cho et al. ${ }^{[69]}$ have provided remarkably clear and detailed experimental insight. They are illustrative of the power of the electrochemical method to inform the mixing properties of liquid metal systems. First the key experimental details pertaining to such set-up are discussed (III-A) and in a second subsection (III-B), typical results are presented and an interpretation in the realm of liquid metal solution is proposed.

\section{A. Experimental Insights}

Both contributions use a concentration cell with a molten electrolyte and $\mathrm{Sn}(\mathrm{L})$ as reference, as reproduced in Figure 2. The study of Te used a $\mathrm{LiCl}-\mathrm{KCl}$ with $2 \mathrm{pct}$ $\mathrm{SnCl}_{2}$ while the study of $\mathrm{Bi}$ used pure molten $\mathrm{SnCl}_{2}$.

Figure 2 shows a container, sealed from the atmosphere with an actively cooled gasket. The container is to be placed in a furnace. The cell itself is at the bottom of the container, located in the isothermal region of the furnace. The thermocouple (chromel-alumel) in the center of the cell informs the temperature and the thermal stability. The reported values are within $0.5 \mathrm{~K}$ to $5 \mathrm{~K}$ in the conditions of Reference 68 . The time to achieve the temperature, and its stability is inherent to the chosen furnace configuration as well as to the thermal mass of the container and the cell. Electrodes that connect the cell to the outside electrical devices, if they are of large diameter, can for example act as heat-sink for the isothermal section of the furnace. Natural convection within the reactor, in particular at very high temperature, can lead to large variation of the cell surface temperature. In short, the thermal engineering of the furnace, reactor and cell are important to provide an experimental set-up that is fast to achieve a stable thermal equilibrium. The underlying challenges and methods to address them can be found with some level of details in textbooks. ${ }^{[70-72]}$ 


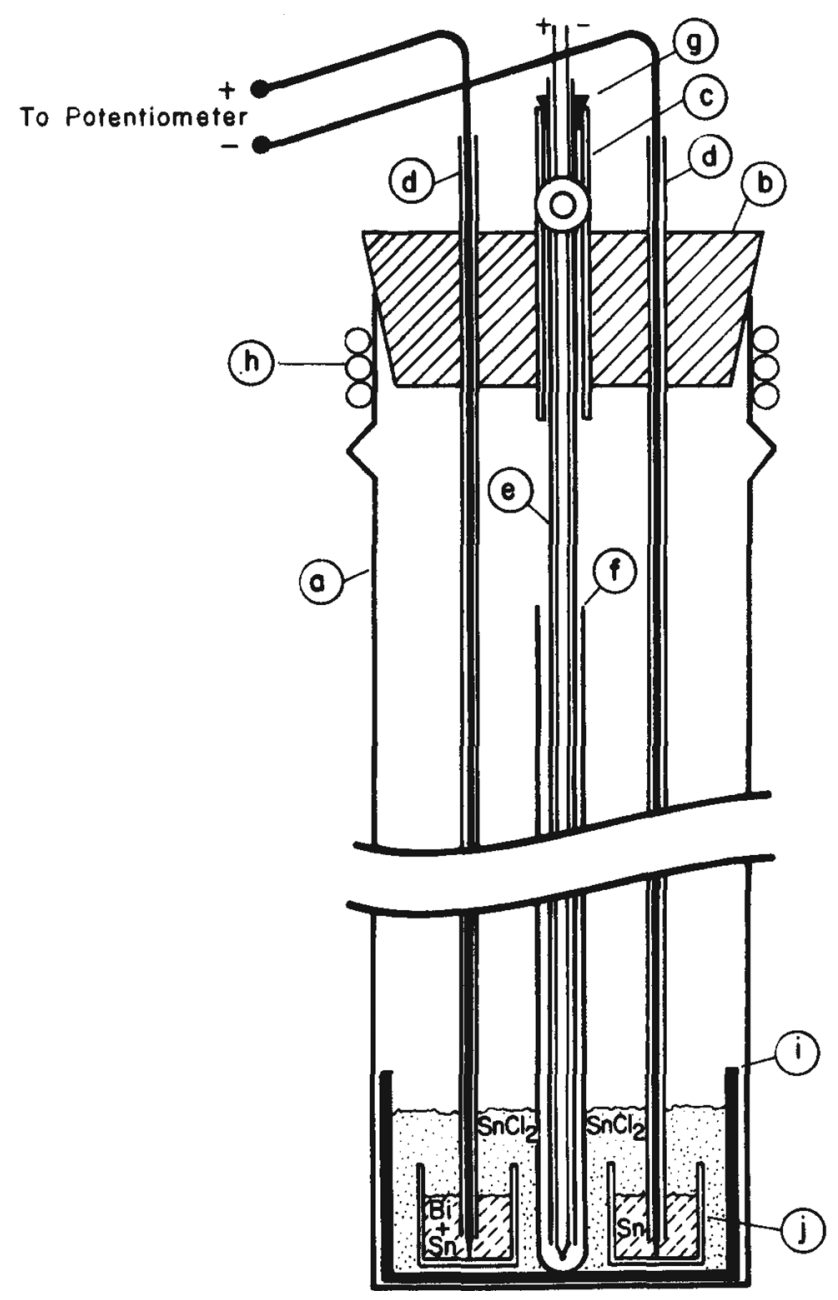

Fig. 2-Example of a concentration cell set-up in for molten halide. Reprinted from Metallurgical Transactions B. ${ }^{[69]}(a)$ and $(f)$ are in Pyrex, $(b)$ provides a seal, cooled by a coil with circulating water $(h)$. (c) has 3 ports, one for a thermocouple and an inlet and outlet for atmosphere control. Ports are equipped with tube fittings $(g)$. The sleeves for the electrode and thermocouple and the crucible $(i)$ and $(j)$, are made of alumina.

Not shown are conventional means to control the atmosphere in the container. The latter is chosen based on the chemical stability of the materials under investigation, the electrode leads and sleeves, and the chosen electrolyte. Metals and liquid electrolyte being very susceptible to reaction with $\mathrm{N}, \mathrm{O}$, or $\mathrm{H}$, it is common to flow a gas of controlled composition (often Ar, available or pre-treated to $<10 \mathrm{ppm} \mathrm{O}_{2}$ ). Of key importance is the preparation of the electrolyte, which for molten salts calls for extensive care for removal of water (e.g., following the procedure described in Reference 73), and of the metals. The latter are often melted several times in very controlled conditions in another apparatus, to reach targeted composition before being assembled into the cell.

Achievement of equilibrium at the chosen temperature is at the heart of the method. This can be verified by monitoring the cell voltage variation with time, where a steady value is an indication of static electrochemical equilibrium. The time required to achieve equilibrium depends on the state of the electrolyte (solid, molten), the geometry of the cell, and the care of preparation and assembly. It is common to stay at given conditions for as long as necessary for the time-averaged value of the cell voltage to be constant within few $\mathrm{mV}$. The duration for this is of the order of several 10 seconds of minutes.

'Often in high temperature system, the governing choice of timescale is the time until something fails. The higher the temperature, the higher the chances that an interface, a gasket or a solid materials deform enough to lead to failure. This failure shall not dismiss the results obtained until its occurrence, but this time-to-failure must be considered when deciding what is the appropriate experimental time to verify equilibrium.

Authors in Reference 69 informed their choice of cell configuration by actual experiments, reporting that a solid-state electrolyte cell proved practically too unstable despite a waiting time of several days. With the molten electrolyte configuration at the composition $\mathrm{Bi}_{0.4} \mathrm{Sn}_{0.6}$ and $723 \mathrm{~K}$, they report $E_{\text {cell }}$ at $14.6119 \mathrm{mV}$ with a time variation of $\pm 0.0052 \mathrm{mV}$ over 3 hours. Once a steady value has been recorded, it is common to test the stability of the overall cell (electrochemical reversibility) by perturbating the electric current in either direction. This perturbation is conventionally a small current step (nA), short enough not to modify the electrolyte and electrodes composition. A return to the initial steady value of the cell voltage after this step is considered an additional criterion of internal equilibrium. This opportunity to perturb the current and force a new electrochemical equilibrium is at the basis of titration and other voltammetric methods, as discussed in a later section.

After a steady value at a given temperature is obtained, the cell temperature can be modified to a new setpoint. This enables the measurements of $E_{\text {cell }}(T)$ upon heating and cooling, i.e., the basis to inform the variation of $\mu_{\mathrm{B}}$ with temperature and a direct measure of the entropy as expressed by Eqs. [10] and [13a], [13b]. The time to achieve the new thermal and electrochemical equilibria follows similar considerations as above. This sequence may be repeated with several batches of the materials at the composition of interest (A-B) so that the reproducibility related to the preparation of the alloy and cell assembly can be assessed, though such efforts are rarely reported.

\section{B. Experimental Results and Interpretation}

Figure 3 is an example of $E_{\text {cell }}$ from Reference 68, for various compositions across the binary $\mathrm{Sn}-\mathrm{Te}$ and as a function of temperature. The authors conducted measurements for temperatures as low as the liquidus, which can be determined very precisely with a molten electrolyte configuration where $\mathrm{Sn}(\mathrm{L})$ is the reference electrode.

Figure 3 shows that the voltage does not vary linearly at all temperatures, an indication of somehow complex entropy variation, certainly a departure from ideal mixing. The trends closer to the liquidus differ from 


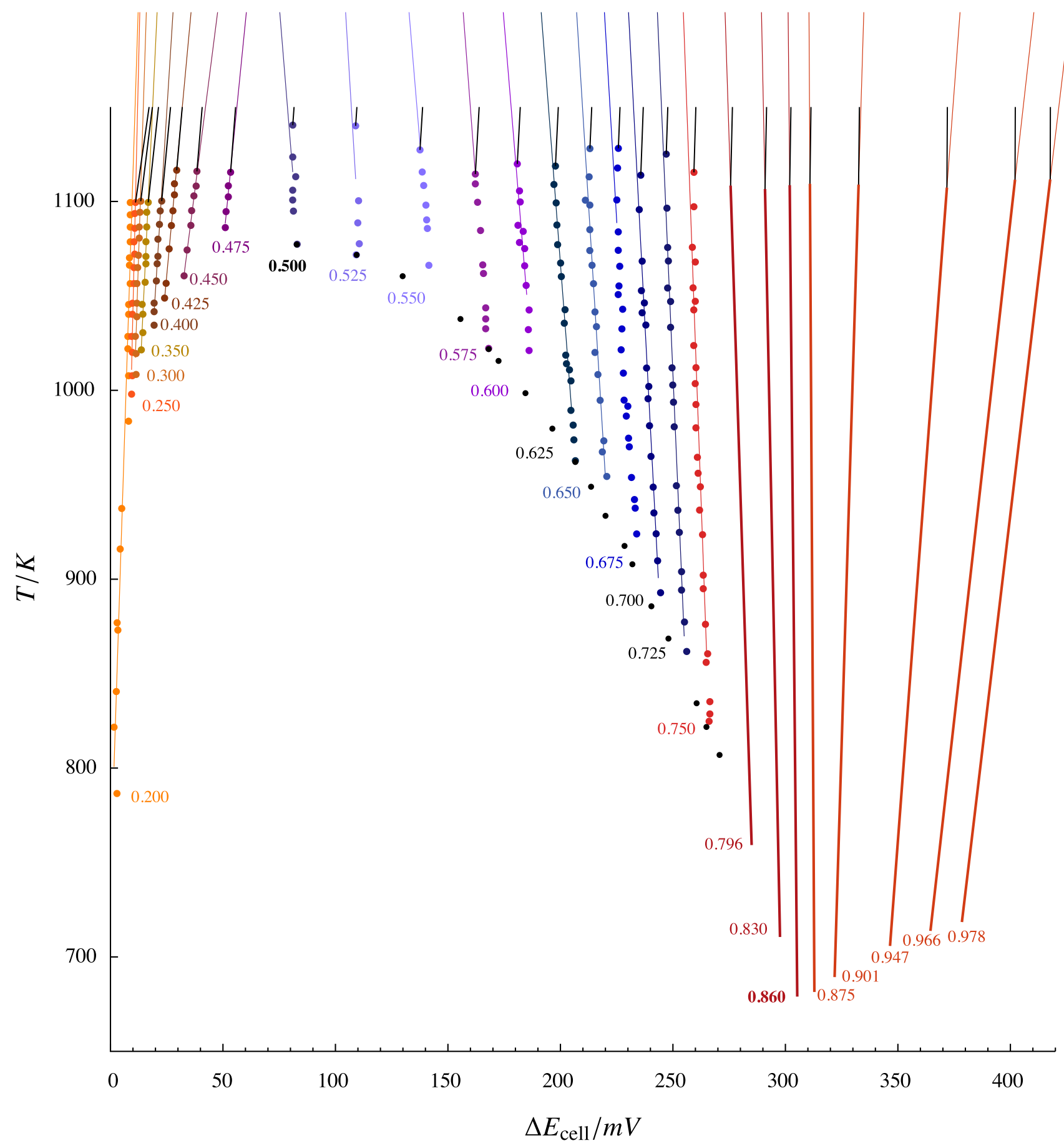

Fig. $3-E_{\text {cell }}$ variation with temperature for the liquid binary Sn-Te from Ref. [68]. Black circles are points reported at the liquidus. Labels are atom fraction content in Te (in bold the congruent melting (0.500) and eutectic (0.860) compositions). Colored lines are linear fits, the thin lines being from Ref. [68] and plain lines extrapolated from Ref. [48] which used the same cell. The black lines represent the ideal entropy of mixing (Color figure online).

trends at high temperature. The linear slopes are also varying as the composition spans from Sn toward Te, though not following the ideal behavior. The slopes are increasingly positive as the Te content increases, tending toward the ideal behavior, found at the congruent melting compound composition $\mathrm{Sn}_{0.5} \mathrm{Te}_{0.5}$. At that composition, virtually no dependence of $E_{\text {cell }}$ is found with temperature, while slopes are increasingly negative for higher content in Te until the eutectic composition at around $x_{\mathrm{Te}}=0.85$. A careful look at compositions between the compound and the eutectic reveals slopes that are actually not fully constant with temperature. 
Those results illustrate the remarkable insight into properties of mixing (here activity and entropy) provided by electrochemistry for what is considered a single liquid in the phase diagram, at temperatures both close and far from the liquidus. As illustrated in Reference 69, and using Eqs. [13a] and [13b] departure from the slope of the cell voltage with temperature ${ }^{\pi \tau}$ from $-R / F \log x_{\mathrm{B}}$

\footnotetext{
${ }^{\top \top}$ Assuming the reference electrode compartment does not undergo a first order phase transformation.
}

is evidence of non-ideality; an activity coefficient $\gamma_{\mathrm{B}}$ that is non unity. Darken and Gurry ${ }^{[74]}$ introduced the $\alpha$ function (sometime referred to as the excess stability function) to illustrate the mixing behavior of solutions at a fixed temperature:

$$
\alpha_{\mathrm{B}}=\frac{\ln \gamma_{\mathrm{B}}}{\left(1-X_{\mathrm{B}}\right)^{2}}
$$

The variation of $\alpha_{\mathrm{Te}}$ at $1100 \mathrm{~K}$ calculated from the results of Reference 68 is presented Figure 4. A trough in the $\alpha$ function is observed at the congruent melting composition starting from pure Sn, revealing a strong chemical interaction even with small addition of Te. A change of curvature is observed at $\mathrm{Sn}_{0.5} \mathrm{Te}_{0.5}$, a feature analogous to a chemical reaction, and postulated to occur centered on the stoichiometry of possible liquid associate complexes. ${ }^{[75,76]}$ At the eutectic composition and for higher Te content, the data are more scattered though somehow with less variation with concentration. Utilizing excess stability,

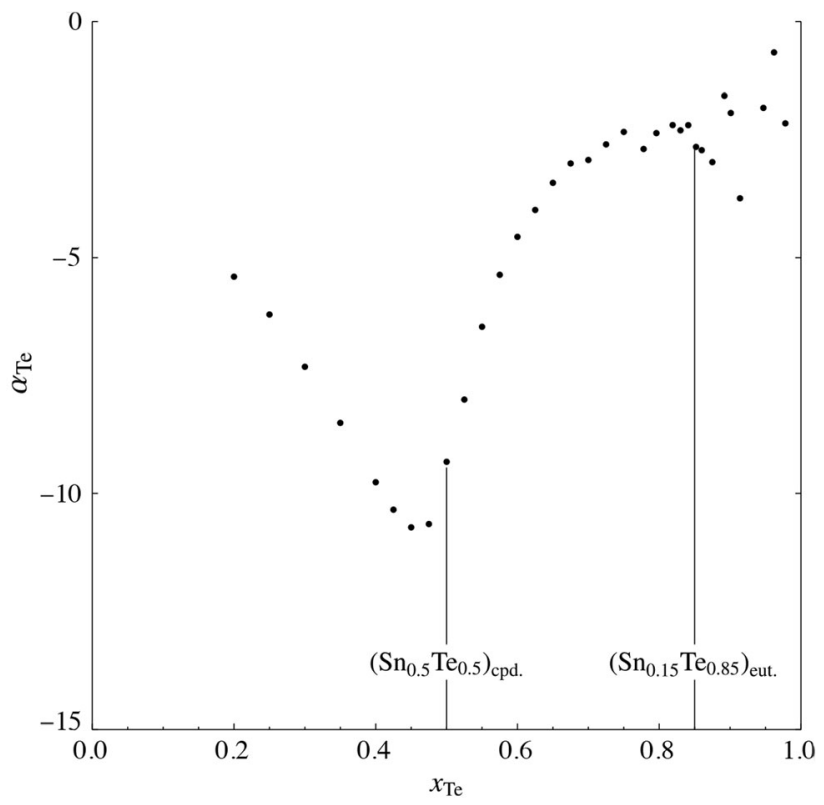

Fig. 4-Excess stability function $\alpha_{\mathrm{Te}}$ at $1100 \mathrm{~K}$ calculated from the data of Fig. 3. ${ }^{[68]}$ The composition of the highest temperature solid compound $\left(\mathrm{Sn}_{0.5} \mathrm{Te}_{0.5}\right)_{\mathrm{cpd}}$. and eutectic $\left.\left(\mathrm{Sn}_{0.15} \mathrm{Te}_{0.85}\right)_{\mathrm{eut}}\right)$ are indicated with vertical lines. the Bhatia-Thornton structure factor in the long wavelength limit can be calculated. ${ }^{[76]}$ It is an atom-centered descriptor of structure accessible from fitting high-energy diffraction data to compute a radial distribution function. The function has found some use in the statistical mechanics fit of inter-atomic energy potentials for macroscopic thermodynamic potential computation.

The values and precision in $E_{\text {cell }}$ and $T$ establish experimental precision and accuracy of the Gibbs energy following Eq. [9], within less than $1 \mathrm{~kJ} / \mathrm{mol}$ of solution. The activity is measured within 10 pct considering the typical experimental errors reported at $1000 \mathrm{~K}$.

To compare or inform solution models with the measured data, a linear regression of $E_{\text {cell }} v s$ temperature is commonly performed as illustrated in Figure 3, the parameters of which are reported as estimates of $H_{\mathrm{B}}^{\mathrm{M}}$ and $S_{\mathrm{B}}^{\mathrm{E}}$ following:

$$
G_{\mathrm{B}}^{\mathrm{E}}=H_{\mathrm{B}}^{\mathrm{M}}-T \times S_{\mathrm{B}}^{\mathrm{E}}
$$

The excess properties, which are partial molar quantities, enable computation of the integral mixing properties. The standard deviation of the linear regression according to Eq. [15] is often reported next to the enthalpy or entropy data. The meaning of this deviation assumes that the model is physically correct, i.e., $H_{\mathrm{B}}^{\mathrm{E}}$ and $S_{\mathrm{B}}^{\mathrm{E}}$ are independent of temperature, ${ }^{*}$ and that the experimental cell

\footnotetext{
*This is equivalent to $\gamma_{\mathrm{B}}$ being independent of temperature, or that the excess heat capacity is $0 .{ }^{[77]}$
}

voltages are sufficiently sensitive to the controlled variable, here the temperature. Equations [13a] and [13b] show that the error propagation is a-priori non-linear, and that the error in $H_{\mathrm{B}}^{\mathrm{M}}$ is highly sensitive to the precision in temperature. The error may be accentuated if data close or near the liquidus are used for the linear fit of $E_{\text {cell }}$ with temperature. As such, it is common to state that the electrochemical method is not the best method to access enthalpies, ${ }^{[78]}$ which are typically informed by calorimetry. As a matter of fact, controversial enthalpy data have been reported using the electrochemical method (e.g., References 69 vs 79), though for $\mathrm{Bi}$, a metal known for its intricate liquid behavior. ${ }^{[80]}$

Despite those limitations, the equilibrium electrochemical method is recognized as the most sensitive to measure Gibbs energy. With this knowledge one can determine the Gibbs energy of mixing, evaluate phase stability, and inform processing models (e.g., undercooling/superheating, nucleation and growth, surface tension, interfacial properties). While the static method reviewed above shows great prospects, its ability to inform transport properties is limited and it often requires a new experiment for each composition. The following section discusses some application of the dynamic electrochemical methods that have offered to alleviate those limitations. 


\section{DYNAMIC ELECTROCHEMICAL POTENTIAL MEASUREMENT METHODS}

An electrochemical cell illustrated in Figure 1 can be displaced to a new equilibrium by temperature, as discussed above, but also by the application of an external cell voltage. This is the basis of electrorefining, electrolysis or galvanic batteries. The external voltage can force a net current in the electrochemical cell such that in principle, B can be transferred in and out of the electrolyte, for example out of the reference electrode into the alloy of study. Such electrochemical reactions in-situ can dynamically modify the concentration of alloying element in the materials of study. This alleviates a limitation of the static method where a new cell is needed for each composition of interest. Thanks to the dynamic nature of such methods, not only equilibrium thermodynamic but also transport properties such as diffusivity can be inferred. This is the basis of the coulombic titration method, reviewed below (IV-A). Even more dynamic, provided that the electrolyte and reference compartments are chemically amenable to it, the electrolyte itself can be decomposed. This is commonly conducted in a formation cell and the method is then called decomposition voltage measurement, as reviewed under Voltammetry (IV-B), where both direct and alternating current methods are discussed.

\section{A. Coulombic Titration}

A known current $(i)$ is forced to flow for a given amount of time $(\Delta t)$ across the cell, and the corresponding charge determines the amount of $\mathrm{B}\left(\Delta n_{\mathrm{B}}\right)$ transferred to the alloy of study following Faraday's law as expressed in Eq. [16]:

$$
\Delta n_{\mathrm{B}}=\frac{i \Delta t}{F}
$$

This assumes $i$ is solely of ionic nature in the electrolyte and only B is electrochemically active as a monovalent species. The current is typically applied as a step function of time until the desired amount of $\mathrm{B}$ is transferred. As an illustration, one milliampere of current for three minutes bring $1.87 \times 10^{-6}$ moles of $\mathrm{B}$, an increase of around $100 \mathrm{ppm}$ for an initial amount of $1 \mathrm{~g}$ of equimolar $\mathrm{A}-\mathrm{B}$ of equal molar mass of $55 \mathrm{~g} / \mathrm{mol}$. The acceptable magnitude for the current scales with the electrode surface areas that are electrochemically active, as determined by the cell configuration. The fundamental limit is the rate-limiting step for the overall electrochemical reaction of the cell. It can be the rate of electron transfer at either electrode (kinetic) or the rate of $\mathrm{B}$ transport in either the electrodes or the electrolyte. The corresponding minimum thermodynamic voltage, assuming ideal mixing behavior in Eq. [10] and pure B is the reference, is $-0.793 \mathrm{~V}$ at $1000 \mathrm{~K}$. The actual voltage necessary to achieve the new amount of B may be of larger magnitude due to resistance to current flow in the electrolyte (ohmic drop) and contact resistances. Those resistances can be measured, for example with impedance spectroscopy using a potentiostat or from the current interrupt method. ${ }^{[81,82]}$ In practice, maintaining a relatively small current density across an electrolyte of relatively high conductivity often allows one to neglect this contribution.

Successful examples from surveyed contributions include oxygen in metals with a solid oxide electrolyte e.g., References 24 and 83, the basis of the Solid Oxide Membrane anode process ${ }^{[84]}$ Success with liquid metal alloys using a molten salt such as $\mathrm{Mg}$ in $\mathrm{Sn}$ e.g., Reference 44 are also reported.

Importantly, the time necessary for the cell to reach a new steady cell voltage with charge informs the rate of transfer of B into the alloy, and helps estimating the diffusivity in the mass transport limiting process. The diffusion phenomena can be studied, such as extensively reported in liquid metals ${ }^{[85-89]}$ or in molten electrolytes. ${ }^{[90,91]}$

\section{B. Voltammetry}

An extension of the coulombic titration method is to vary the current continuously and conduct actual electrolysis, such as found in a formation cell, where the electrolyte is actively decomposed. In this situation the electrochemical equilibrium is (thermodynamically) irreversibly displaced. One possible configuration involving liquid metal is presented in Figure 5.

A net current then drives simultaneously the anodic Reaction 17 of gas evolution from the electronegative species $\mathrm{X}^{-}$, for example on a graphite counter electrode (CE). Simultaneously, the cathodic reduction 18 of the electropositive $\mathrm{B}^{+}$in the liquid working electrode (WE) is conducted. The cell runs the electrolytic decomposition of BX following Reaction 19:

$$
2 \mathrm{X}^{-} \rightarrow \mathrm{X}_{2}(\mathrm{~g})+2 e^{-}
$$

$$
2 \mathrm{~B}^{+}+2 e^{-} \rightarrow 2 \mathrm{~B}(1)
$$

$$
2 \mathrm{BX} \rightarrow 2 \mathrm{~B}(\mathrm{l})+\mathrm{X}_{2}(\mathrm{~g})
$$

Several additional materials constraints are apparent. First a stable gas evolving anode needs to be available. Second the electrolyte needs to accommodate both the transfer of B and X, along with supporting the Reaction rates of both Reactions 17 and 18. Therefore, the electrolyte is often molten and contains multiple components that are electrically active but not electrochemically reactive at the conditions of the measurement; a supporting electrolyte.

Enabling and mastering such conditions require special care, as discussed early by Ellingham ${ }^{[94]}$ and efforts in this direction have led to very important insights into the reducibility of compounds which support modern extractive metallurgy. Very often such cells are formed using molten salt electrolytes ${ }^{[95]}$ because 

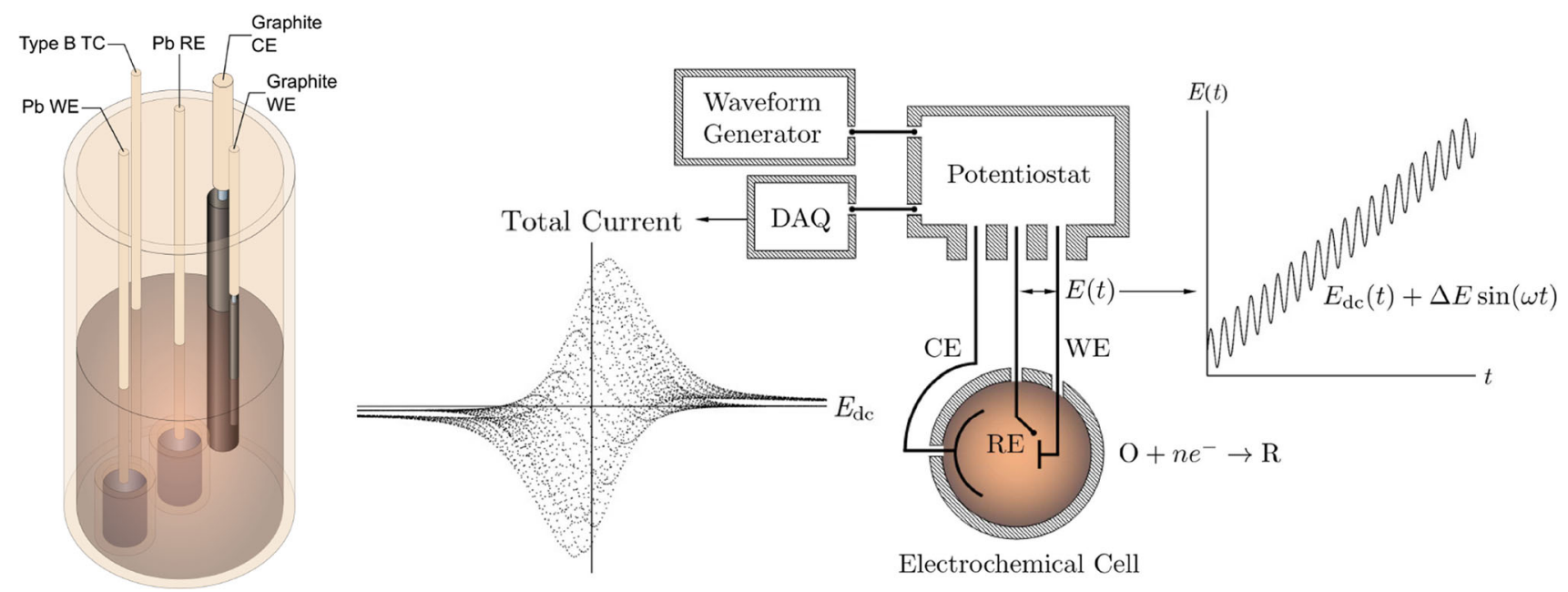

Fig. 5-Principles of voltametric methods. ${ }^{[92,93]}$ Left, cell used to investigate liquid lead deposition from $\mathrm{PbCl}_{2}$ decomposition in molten chlorides using voltammetry - note the addition of a Reference Electrode (RE). A graphite working electrode (WE) is used to electrolyze impurities and verify the electrolyte electrochemical behavior. The $\mathrm{Pb} \mathrm{WE}$ is used for actual measurements. Right, electrical connections and devices used to conduct DC and AC voltammetry. A potential $E(t) \mathrm{DC}+\mathrm{AC}$ waveform is shown to the right of the cell, and the corresponding total current recorded with a Data Acquisition (DAQ) is shown to the left.

their relatively high temperature supports operation with liquid metal, fast electrode reaction kinetics, high conductivity and fast rate of mass and charge transport.

Because the cell is now dynamically out of equilibrium, irreversible phenomena have to be considered to decipher the equilibrium thermodynamic contribution $\left(E_{\text {cell }}^{\text {eq. }}=-\Delta G_{19} / 2 F\right)$ from the overall cell voltage $E_{\text {cell: }}$ :

$$
E_{\mathrm{cell}}=E_{\mathrm{cell}}^{\mathrm{eq}}+i R_{\mathrm{u}}+\eta_{\mathrm{mt}}+\eta_{\mathrm{ct}}
$$

Three irreversible terms are added to the equilibrium thermodynamic cell voltage. The uncompensated resistance of the cell $R_{\mathrm{u}}$ is determined by the geometry and electrochemical transport properties of the supporting electrolyte. Often, if gas is evolved at the CE (anode) at high current density, the electrical resistance will increase due to the limiting rate of gas removal from the electrolyte. This is one example where the CE reaction, necessary to complete the electrochemical circuit, could limit the range of current accessible to the cell, itself affecting the rate of $\mathrm{B}$ transferred at the WE (cathode). Mass transport $\left(\eta_{\mathrm{mt}}\right)$ and charge transfer $\left(\eta_{\mathrm{ct}}\right)$ contributions, representing the additional driving force necessary to accommodate limitations in mass transport and electron transfer limitations, encompass anode and cathode reaction contributions. Those are commonly separated in electrochemical kinetic studies.

\section{DC Methods}

With such considerations, the variable experimentally controlled is the overall cell voltage $E_{\text {cell }}$ which leads to the establishment of a current $i$, a steady-measurement of which indicates new electrochemical equilibrium. Measurements in steady-state of the cell voltage for various levels of constant current (galvanostatic), or various temperature at a given current, often exhibit a linear variation of $E_{\text {cell }}$ with $i$, as illustrated in Figure 6. It illustrates results for aluminium electrolysis in cryolite,${ }^{[96]}$ using liquid aluminium at the cathode and graphite as an anode. Extrapolation at zero current provides an estimate of $E_{\text {cell }}^{\text {eq. }}$ as it pertains to the cell under investigation. In this specific example, ${ }^{[96]}$ no analysis of the thermodynamic nature of $E_{\text {cell }}^{\mathrm{eq}}$ was provided. Nevertheless, the analysis of such findings in the context of industrial engineering highlighted the departure from a linear effect of temperature on the actual cell voltage, as shown at low current for the highest temperature in Figure 6.

Using only 2 electrodes that are electrochemically active and dynamically polarized simultaneously indeed introduces difficulty in the interpretation of trends with current and temperature. It is therefore common to add a third electrode to the cell, called a reference electrode (RE), which is used to monitor individual electrode potentials $\left(\mu_{e^{-}}^{(+)}-\mu_{e^{-}}^{\text {ref. }}\right)$ and $\left(\mu_{e^{-}}^{(-)}-\mu_{e^{-}}^{\text {ref. }}\right)$ independently from the working and counter electrode reactions. As shown in Figure 5, this additional electrode $\mathrm{RE}$ is located in the electrolyte. Its choice and operation obey very similar rules of design and operation as an equilibrium electrochemical cell discussed in Section II-A. Dedicated literature is available to describe the thermodynamic and practical considerations for reference electrode materials. ${ }^{[98]}$ Of note, there are not many reference electrodes accepted as such in the field of high temperature electrochemistry, though molten chlorides seem better equipped with for example $\mathrm{Ag} / \mathrm{AgCl}$. Often at high temperature, a quasi-reference electrode is used instead. Those comprise a metal in equilibrium with a fix concentration of its soluble ion (see for example pure lead in Figure 5 or dysprosium metal in Figure 6) or a metal which develops a chemically active, though thin (passive) layer; a metal covered with its compound which kinetic of growth is slow and solubility is quickly achieved with the electrolyte. A lack of 

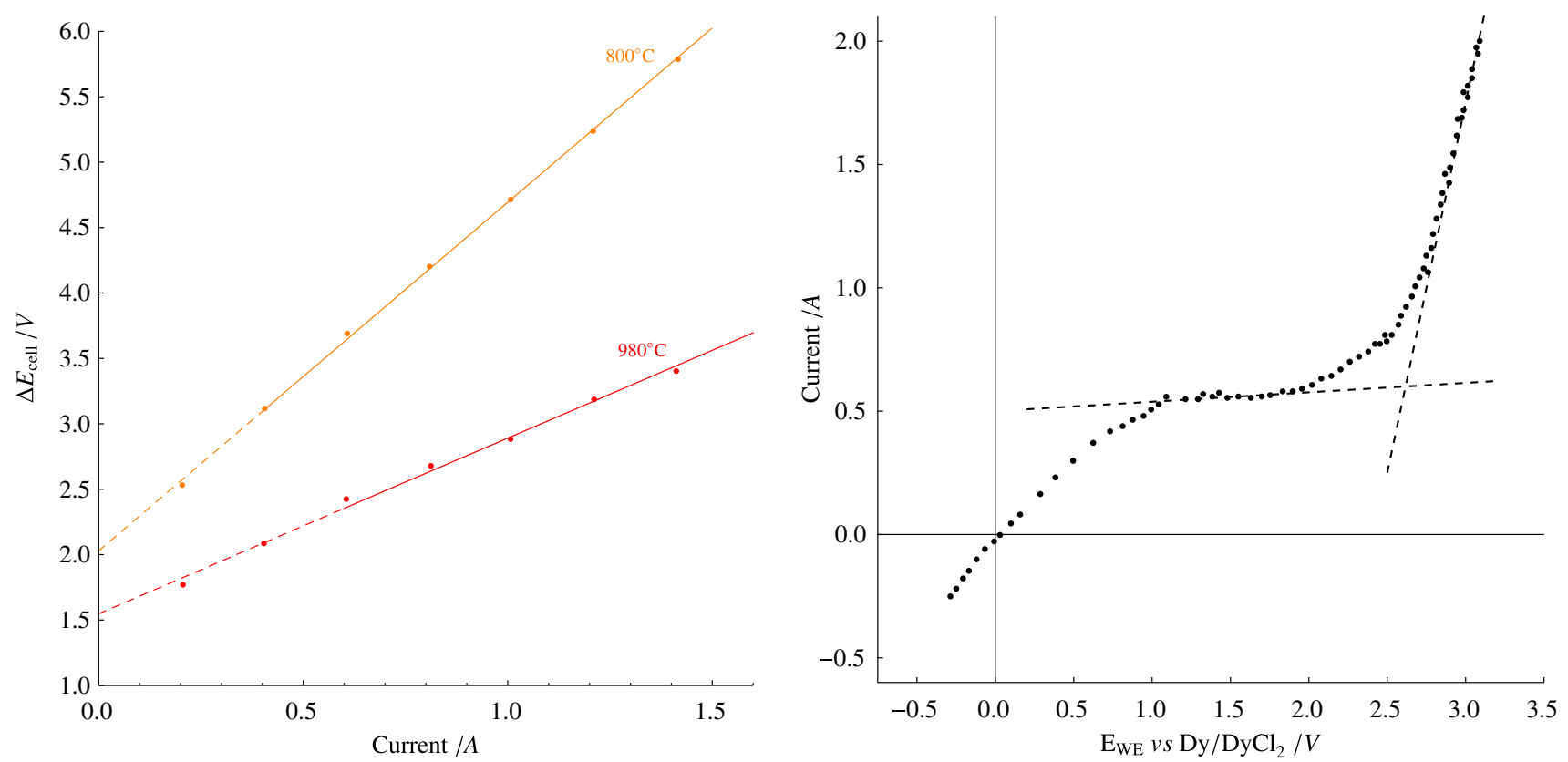

Fig. 6-Results from DC methods. Left, variation of the cell voltage with the current for alumina decomposition to aluminum in cryolite at two different temperatures, replot with permission from Ref. [96]. Right, voltammetry showing the decomposition of dysprosium chloride in molten $\mathrm{DyCl}_{2}-\mathrm{MgCl}_{2}$ replot with permission from Ref. [97] at $1073 \mathrm{~K}$, where the current plateau at around $0.5 \mathrm{~A}$ is attributed to Dy ${ }^{2+}$ oxidation to $\mathrm{Dy}^{3+}$, and the wall for chlorine evolution is visible for potential greater than $2.5 \mathrm{~V}$. The potential corresponding to the intersection of the dotted lines, referred to the null potential for $\mathrm{Dy} / \mathrm{DyCl}$, is a proxy to the decomposition potential of $\mathrm{DyCl}_{2}$ in solution with $\mathrm{MgCl}_{2}$.

research toward reference electrodes is an impediment to a broader application of the dynamic electrochemical methods for high temperature.

The two additional $\eta$ terms in Eq. [20] have a non-linear dependence with the current. $\eta_{\mathrm{mt}}$ is the mass transport overpotential, and $\eta_{\mathrm{ct}}$ is the charge transfer overpotential of the cell. Again individual electrode contributions, experimentally accessible thanks to the use of a reference electrode, are frequently distinguished. Electroanalytical and chemical methods help to establish the critical cell voltage at which simultaneous establishment of the anodic reaction (e.g., $\mathrm{X}_{2}$ evolution from an electrolyte $\mathrm{BX}-\mathrm{CX}$ in Figure 1) and metal $\mathrm{B}$ cathodic reduction are initiated. This is possible in conditions where $i R_{\mathrm{u}}+\eta_{\mathrm{mt}}+$ $\eta_{\mathrm{ct}}$ are quantifiable either directly via independent experiments or from available models.

Time is now a key additional variable, i.e., the voltage may be scanned from its zero current (equilibrium) value to a chosen value at any arbitrary rate. Direct current (DC) voltammetry imposes a linear time profile $E_{\text {cell }}(t)$, typically 1 to $100 \mathrm{mV}$ per second, and measures the corresponding variation of the DC current. The voltage sweep can be conducted in both the positive and negative potential directions, possibly in cycles (cyclic voltammetry). If a reference electrode is used, a plot of the variation of the DC current with the WE potential is obtained, an example of which is shown in Figure 6 from Reference 97. In that work, the potential was measured vs the RE, pure Dy metal assumed to be at equilibrium with $\mathrm{DyCl}_{2}$. Dedicated textbooks for the electrochemical interpretation of the corresponding potential-current variations for such DC methods are available, ${ }^{[99-101]}$ though they are mostly concerned with the kinetic (charge transfer) interpretations and limitations that are inherent to low-temperature electrolytes. Those are less important for molten electrolytes and liquid metals, as for those conditions mass-transfer effects dominate.

DC methods have been used to inform the properties of molten electrolytes, to evaluate the Gibbs energy of formation of a salt ( $\mathrm{DyCl}_{2}{ }^{\left[{ }^{[7]}\right)}$ or the chemical potential (activity) of dissolved species from molten oxides. ${ }^{[102,103]}$ They also have been used to inform diffusion and new solid formation in a metal cathode in molten salts ${ }^{[104-106]}$ or the interaction between hydrogen and a metal cathode. ${ }^{[73]}$ The latter is one example where electrochemistry is used to inform metal thermodynamics. Just the same there have been relatively few studies that used dynamic electrochemical methods as a means to determine the liquid alloy properties from well-established electrolyte properties. In addition to the difficulties in devising and constructing an actual cell that is sufficiently robust for several hours of investigations, a particular challenge is the proper identification of the potential at which the metal is deposited at or close to its thermodynamic potential. Indeed, as noticed in Figure 6, the ability to define with precision the onset of the electrochemical reaction, chlorine gas evolution in that example, is often subject to interpretation with cyclic DC voltammetry. 

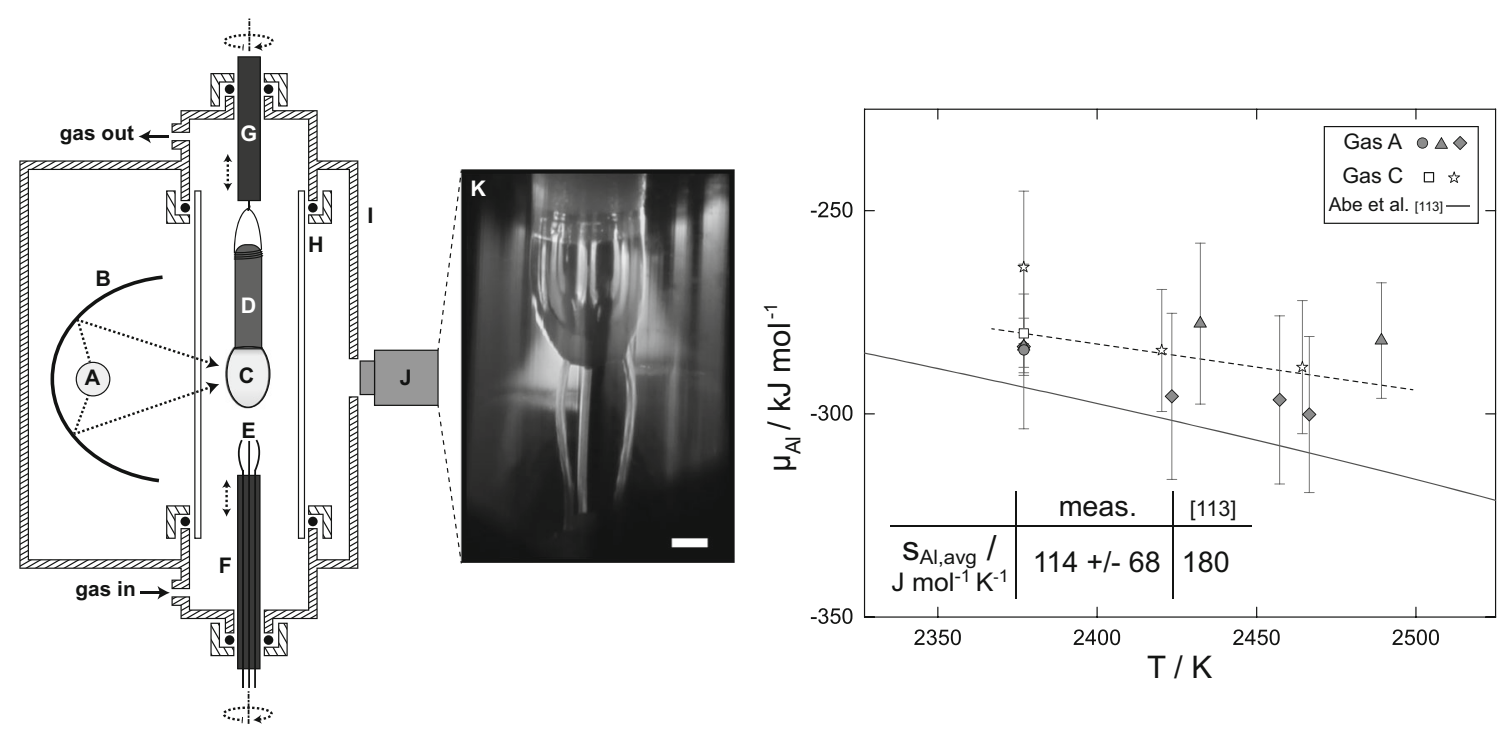

Fig. 7-AC method applied in a container-less set-up at temperature above $2100{ }^{\circ} \mathrm{C}$, reprinted with permission from the Journal of the Electrochemical Society. ${ }^{111,112]}$ Left, schematic of a floating zone furnace setup, (A) Xe lamp and (B) mirror, (C) molten electrolyte pendant droplet $\left(0.1\right.$ to $\left.1 \mathrm{~cm}^{3}\right)$, (D) solid electrolyte $(\mathrm{E})$ electrodes, $(\mathrm{F})$ electrode leads and lower shaft, $(\mathrm{G})$ upper shaft, (H) quartz tube, (I) furnace shell, (J) camera, and $(\mathrm{K}) \mathrm{Ir}$ electrodes inserted into molten $\mathrm{Al}_{2} \mathrm{O}_{3}$ (scale bar $2 \mathrm{~mm}$ ). Right, chemical potential and entropy estimates for $\mathrm{Al}$ in liquid Al-Ir at the solid-liquid boundary using the ACV method combined with the overall cell voltage measurement from the left set-up, compared to the most recent thermodynamic assessment. ${ }^{[113]}$

\section{AC Methods}

To identify the equilibrium thermodynamic potential at which reactions occur, it has been suggested early to use dynamic alternating current (AC) methods. ${ }^{[107]}$ Advances in power electronics and digitization of electrical signals make this an accessible modern tool for experimentalist. The superposition of an AC perturbation of potential on the DC potential ramp as in Alternating Current Voltammetry (ACV) enables a frequency analysis of the corresponding current, ${ }^{[108]}$ as illustrated in Figure 6. For example a sinusoidal waveform of amplitude $\Delta E$ and frequency $\omega$ is superimposed on a linear $E_{\text {cell }}(t)$. This enables a clear distinction between the various electrical and chemical events that support the variation of $i$ vs $E$, by choosing a frequency that enhances the intensity of Faradaic contributions. This has been recognized early for dynamic methods such as voltammetry, as applied for electrodeposition in molten salts, though the underlying theory was limited to a soluble redox reactions ${ }^{[109]}$ or infinitely dilute metal deposition in a liquid host, ${ }^{[110]}$ conditions where $\mathrm{B}$ reduction is diffusion controlled. This is likely not appropriate for concentrated liquid metal alloys, and a recent contribution has provided a model that is applicable for such conditions. ${ }^{[16]}$ The model was validated with lead deposition into lead in molten $\mathrm{NaCl}-\mathrm{KCl}-\mathrm{PbCl}_{2}$ where the species undergoing reduction is a divalent lead ion. The method demonstrated that precise and readily identifiable features of the harmonic AC current response provide access to thermodynamic equilibrium potentials. In particular, the potential of the peak in the second harmonic current $\left(E_{\text {peak }}\right)$ can be readily identified, and relates to activity coefficients following:

$$
E_{\text {peak }}-E^{\circ}=-\frac{R T}{n F} \ln \left(2 R_{\mathrm{u}} \kappa\right)
$$

where

$$
\kappa=\frac{n^{2} F^{2} A\left(\omega D_{\mathrm{Pb}^{2+}}\right)^{1 / 2} C_{\mathrm{Pb}^{2+}}^{0} .}{\gamma_{\mathrm{Pb}^{2+}} R T} .
$$

In Eq. [21], $E^{\circ}$ is the standard state potential for the half-reaction, where the thermodynamics standard state for $\mathrm{Pb}^{2+}$ and $\mathrm{Pb}$ have to be carefully but arbitrarily chosen. ${ }^{[16]}$

If the resistance of the electrolyte $\left(R_{\mathrm{U}}\right)$ is measured and the active surface area $A$ is known, Eq. [22] contains the entire physical-chemical (diffusivity $D_{\mathrm{Pb}^{2+}}$ ) and thermodynamic (bulk concentration $C_{\mathrm{Pb}^{2+}}^{0}$, activity coefficient $\gamma_{\mathrm{Pb}^{2+}}$ ) properties of the species being reduced. This shows that the precision in the activity coefficient scales with the precision in the determination of the peak potential. A precision from 1 to $10 \mathrm{mV}$ is achievable, corresponds to an uncertainty in the activity coefficient similar to the one observed for the static electrochemical method at $1000{ }^{\circ} \mathrm{C}$. While demonstrated in Reference 16 to inform the thermodynamic properties of the electrolyte, the method can be applied with a well-known electrolyte to inform the thermodynamic of metal solution cathode products.

A recent application of the ACV method coupled with a container-less set-up investigated molten alumina at around $2100{ }^{\circ} \mathrm{C}$ using 3 iridium electrodes, ${ }^{[111]}$ as shown in Figure 7. The ACV method was applied to both the anodic (oxygen evolution) and cathodic (aluminum deposition) reactions using the same reference electrode, 
to provide thermodynamic decomposition voltages. This itself informed the Gibbs energy of the very high temperature $\mathrm{Ir}-\mathrm{Al}$ alloys. This was possible thanks to the well-established properties of molten alumina. There, oxygen evolution and a quasi-reference iridium are used, enabling a direct measurement of thermodynamics, with pure oxygen, pure iridium solid and pure alumina as reference thermodynamic states. The relative simplicity of those conditions helped inform the chemical potential and partial molar entropy of $\mathrm{Al}$ in $\mathrm{Ir}-\mathrm{Al}$.

Subsequent application ${ }^{[112]}$ of the method to the molten rare-earth oxide binary $\mathrm{La}_{2} \mathrm{O}_{2}-\mathrm{Y}_{3} \mathrm{O}_{3}$ at around $2300{ }^{\circ} \mathrm{C}$ provided insights into the solution behavior of the electrolyte, though extension of the data to the properties of the liquid cathode was limited by the amount of knowledge of the thermodynamic of molten rare-earth oxides and liquid iridium.

\section{SUMMARY}

Modern metals extraction and production as well as materials science have been transformed by electrochemistry. Herein the contributions highlighted from Metallurgical Transactions dedicated to liquid metals thermodynamics reveal the breadth of quantitative and qualitative insights that are possible thanks to the diversity of electrolytes that can be conceived. In addition to innovation in electrolytes for greater range of temperature, chemical gradients, or the transport of anions beyond oxygen, the deployment of DC and AC voltammetry is getting more attention for studies of systems operating under extreme conditions, i.e., high temperatures, reactive metals, nonaqueous electrolytes.

Some of the experimental challenges highlighted herein have become easier to overcome, in particular in the USA, thanks to the reliable supply of materials of construction of higher purity, the laboratory availability of better electronic controllers for furnaces and potentiostats, and easier methods for atmosphere controls. While those do not alleviate the need for dedication, care and patience to build reliable electrochemical cells, those efforts are well rewarded by the wealth of information accessible once a cell is stable in temperature. Indeed, in addition to providing Gibbs energy, electrochemistry offers a unique access to measurements of entropy or chemical ordering, which are frontiers in the fundamentals of condensed matter, solid or liquid. Furthermore, links with transport properties are seen as essential features of electrochemical methods applied with a molten electrolyte or for a liquid metal. Electrochemical methods can provide a different thermodynamic and physical-chemical perspective on metals and materials.

\section{ACKNOWLEDGMENTS}

This review has been conceived while collaborating with Professor Claude H. P. Lupis. His efforts to pro- vide quantitative thermodynamic insights, his interest in linking those with electrochemistry, and his kind support through the years will always be remembered.

\section{REFERENCES}

1. D.J. Bradwell, H. Kim, A.H. Sirk, and D.R. Sadoway: J. Am. Chem. Soc., 2012, vol. 134 (4), pp. 1895-97.

2. J. Rogez: Rev. Métall., 1998, vol. 95, pp. 1047-58.

3. M.G. Frohberg: Thermochim. Acta, 1999, vol. 337, pp. 7-17.

4. K. Hildal and J. Perepezko: in Handbook of Thermal Analysis and Calorimetry, Elsevier, vol. 6, chap. 19, (2006), pp. 71-132.

5. A. Navrotsky: Phys. Chem. Miner., 1977, vol. 2, pp. 89-104.

6. A. Navrotsky: J. Am. Ceram. Soc., 2014, vol. 97 (11), pp. 334959.

7. C.H. Lupis: Chemical Thermodynamics of Materials, 1st ed., Prentice Hall, Englewood Cliffs, NJ, 1983.

8. B. Fultz: Phase Transitions in Materials, Cambridge University Press, Cambridge, 2014.

9. O.J. Kleppa: J. Non-Cryst. Solids, 1984, vols. 61-62, pp. 101-111.

10. A. Miedema, P. De Châtel, and F. de Boer: Physica, 1980, vol. 100B, pp. 1-28.

11. J.N. Pratt: Metall. Trans. A, 1990, vol. 21 (4), pp. 1223-50.

12. D.J. Fray: Metall. Mater. Trans. B Process Metall. Mater. Process. Sci., 2003, vol. 34B, pp. 589-94.

13. H. Ipser, A. Mikula, I. Katayama: Calphad: Computer Coupling of Phase Diagrams and Thermochemistry, 34, 271 - 278 (2010).

14. B.C.H. Steele: in Electromotive Force Measurements in High Temperature Systems, C.B. Alcock, ed., American Elsevier Publishing Company, New York City, NY, pp. 3-27.

15. G.R. Belton and R. Fruehan: J. Phys. Chem., 1967, vol. 71 (5), pp. 1403-09.

16. A.H. Caldwell and A. Allanore: Acta Mater., 2019, vol. 173, pp. $1-8$.

17. R.J. Fruehan: Metall. Trans., 1970, vol. 1, pp. 865-70.

18. C. Stinn and A. Allanore: Metall. Mater. Trans. B Process Metall. Mater. Process. Sci., 2018, vol. 49B, pp. 3367-80.

19. S. Otsuka and Y.A. Chang: Metall. Trans. B, 1984, vol. 15, pp. 337-344.

20. Y. Li, Y.J. Yang, and C.Z. Wang: Metall. Mater. Trans. B Process Metall. Mater. Process. Sci., 2008, vol. 39B, pp. 291-97.

21. C.R. Nanda and G.H. Geiger: Metall. Mater. Trans., 1970, vol. 1 (5), pp. 1235-43.

22. R.J. Fruehan: Metall. Trans., 1970, vol. 1 (August), pp. 2083-2088.

23. R.J. Fruehan: Metall. Trans., 1970, vol. 1 (12), pp. 3403-410.

24. T.H. Etsell and S.N. Flengas: Metall. Trans., 1971, vol. 2 (10), pp. 2829-32.

25. A.D. Kulkarni: Metall. Trans., 1973, vol. 4 (7), pp. 1713-21.

26. A.D. Kulkarni and R.E. Johnson: Metall. Trans., 1973, vol. 4 (7), pp. 1723-27.

27. S. Otsuka and Z. Kozuka: Metall. Trans. B, 1980, vol. 11, pp. 313-19.

28. S. Otsuka and Z.K. Kozuka: Metall. Trans. B, 1980, vol. 11 (1), pp. $119-24$

29. S. Otsuka, H. Hanaoka, and Z. Kozuka: Trans. Jpn. Inst. Met., 1982, vol. 23 (9), pp. 563-70.

30. S. Otsuka and Z. Kozuka: Metall. Trans. B, 1981, vol. 12 (3), pp. 616-20.

31. S. Otsuka, Y. Kurose, and Z. Kozuka: Metall. Trans. B, 1982, vol. 13 , pp. $77-83$.

32. R. Kawabata, M. Ichise, and E. Iwase: Metall. Trans. B, 1995, vol. 26 (August), pp. 783-787.

33. N. Kurita, N. Fukatsu, S. Miyamoto, F. Sato, H. Nakai, K. Irie, and T. Ohashi: Metall. Metall. Trans. B, 1996, vol. 27B, pp. 92935.

34. S. Yao, Y. Kaku, and Z. Kozuka: Metall. Trans. B, 1986, vol. 17 (1), pp. 171-77.

35. M.A. Swetnam, R.V. Kumar, and D.J. Fray: Metall. Mater. Trans. B, 2006, vol. 37B, pp. 381-88.

36. M.W. Barsoum and H.L. Tuller: Metall. Trans. A, 1988, vol. 19 (3), pp. 637-44. 
37. I. Johnson and R.M. Yonco: Metall. Trans., 1970, vol. 1 (April), pp. 905-910.

38. Y.K. Rao and B.V. Patil: Metall. Trans., 1971, vol. 2 (7), pp. 1829-35.

39. Y.K. Rao and G.R. Belton: Metall. Trans., 1971, vol. 2, pp. 2215-19.

40. Z. Moser: Metall. Mater. Trans. B, 1971, vol. 2B, pp. 2175-83.

41. Z. Moser: Metall. Trans., 1973, vol. 4 (10), pp. 2399-405.

42. Z. Moser and C. Krohn: Metall. Trans., 1974, vol. 5, pp. 979-85.

43. Z. Moser: Metall. Trans., 1974, vol. 5 (6), pp. 1445-50.

44. Z. Moser, W. Zakulski, Z. Panek, M. Kucharski, and L. Zabdyr: Metall. Trans. B, 1990, vol. 21 (4), pp. 707-714.

45. S. Karlhuber, A. Mikula, and F. Sommer: Metall. Mater. Trans. B Process Metall. Mater. Process. Sci., 1996, vol. 27B, pp. 92128.

46. B.L. Tiwari: Metall. Trans. A Phys. Metall. Mater. Sci., 1987, vol. 18 (9), pp. 1645-51.

47. H. Sakao and J.F. Elliott: Metall. Trans., 1974, vol. 5 (9), pp. 2063-67.

48. M. Le Bouteiller, A. Martre, R. Farhi, and C. Petot: Metall. Trans. B, 1977, vol. 8, pp. 339-44.

49. R. Benz: Metall. Trans., 1974, vol. 5 (10), pp. 2217-24.

50. J.M. Geldenhuis and R.J. Dippenaar: Metall. Trans. B, 1991, vol. 22 (6), pp. 915-18.

51. T.K. Inouye, H. Fujiwara, and M. Iwase: Metall. Trans. B, 1991, vol. 22 (4), pp. 475-80

52. H. Hoshino, T. Shimada, M. Yamamoto, and M. Iwase: Metall. Trans. B, 1992, vol. 23 (2), pp. 169-73.

53. R. Ushio and O. Ogawa: Metall. Trans. B, 1991, vol. 22 (1), pp. 47-52.

54. H.Y. Choi, W.E. Slye, R.J. Fruehan, and R.C. Nunnington: Metall. Mater. Trans. B Process Metall. Mater. Process. Sci., 2005, vol. 36 (4), pp. 537-41.

55. R. Littlewood: Can. Metall. Q., 1966, vol. 5 (1), pp. 1-17.

56. J.J. Pak, M.L. Santella, and R.J. Fruehan: Metall. Trans. B, 1990, vol. 21 (2), pp. 349-55.

57. L.A. Pugliese and G.R. Fitterer: Metall. Trans., 1970, vol. 1 (7), pp. 1997-2002.

58. P. George, S.C. Parida, and R.G. Reddy: Metall. Mater. Trans. B Process Metall. Mater. Process. Sci., 2007, vol. 38 (1), pp. 85-91.

59. H. Kim, D.A. Boysen, D.J. Bradwell, B. Chung, K. Jiang, A.A. Tomaszowska, K. Wang, W. Wei, and D.R. Sadoway: Electrochim. Acta, 2012, vol. 60, pp. 154-62.

60. T. Lichtenstein, N.D. Smith, J. Gesualdi, K. Kumar, and H. Kim: Electrochim. Acta, 2017, vol. 228, pp. 628-35.

61. N.D. Smith, T. Lichtenstein, J. Gesualdi, K. Kumar, and H. Kim: Electrochim. Acta, 2017, vol. 225, pp. 584-91.

62. T.P. Nigl, N.D. Smith, T. Lichtenstein, J. Gesualdi, K. Kumar, and H. Kim: J. Vis. Exp., 2017, vol. 129, p. e56718, https://doi. org/10.3791/56718.

63. T. Wen, J. Yu, E. Jin, T. Liu, X. Hou, and Q. Sun: Sensors Actuators B Chem., 2018, vol. 279, pp. 177-182.

64. Y. Okuyama, N. Kurita, A. Yamada, H. Takami, T. Ohshima, K. Katahira, and N. Fukatsu: Electrochim. Acta, 2009, vol. 55 (2), pp. 470-74.

65. C. Schwandt: Sensors Actuators B Chem., 2013, vol. 187, pp. 227-233.

66. C. Rinzler and A. Allanore: Philos. Mag., 2016, vol. 96, pp. 304153.

67. C.C. Rinzler and A. Allanore: Philos. Mag., 2017, vol. 97, pp. $561-71$.

68. J. Rakotomavo, M.C. Baron, and C. Petot: Metall. Trans. B, 1981, vol. 12 (3), pp. 461-67.

69. S.A. Cho, R. Camisotti, and M.H. Vélez: Metall. Trans. B, 1990, vol. 21 (1), pp. 87-96.

70. J.O. Bockris, J.L. White, and J.D. Mackenzie, eds.: Physicochemical Measurements at High Temperatures., Butterworths Scientific Publications, London, 1959.

71. K. Motzfeldt: HIgh Temperature Experiments in Chemistry and Materials Science, Wiley, Chichester, 2013.

72. W.D. Kingery: Property Measurements at High Temperatures: Factors Affecting and Methods of Measuring Material Properties at Temperatures Above $1400{ }^{\circ} \mathrm{C}$. $\left(2550^{\circ} \mathrm{F}\right)$, Wiley, New York, 1959.
73. T. Kasajima, T. Nishikiori, T. Nohira, and Y. Ito: J. Electrochem. Soc., 2003, vol. 150(7), p. E355.

74. L.S. Gurry and R.W. Darken: Physical Chemistry of Metals, McGraw and Hill, New York, 1953.

75. M. Saboungi, J. Marr, and M. Blander: J. Chem. Phys., 1978, vol. 68 (4), pp. 1375-84

76. M.-L. Saboungi, W. Geertsma, and D.L. Price: Annu. Rev. Phys. Chem., 1990, vol. 41, pp. 207-44.

77. N. Gokcen: Thermodynamics, Techscience Inc, Hawthorne, CA, 1975.

78. Z. Moser and K. Fitzner: Thermochim. Acta, 1999, vol. 332, pp. $1-19$.

79. N. Asryan and A. Mikula: Z. Metall., 2004, vol. 85, pp. 3-135.

80. M. Emuna, S. Matityahu, E. Yahel, G. Makov, and Y. Greenberg: J. Chem. Phys., 2018, vol. 148(3), p. 034505.

81. J. Newman: J. Electrochem. Soc., 1970, vol. 117 (4), pp. 507-08.

82. W. Oelbner, F. Berthold, and U. Guth: Mater. Corros., 2006, vol. 57 (6), pp. 455-66.

83. K. Goto, M. Someno, M. Sano, and K. Nagata: Metall. Trans., 1970, vol. 1 (1), pp. 23-29.

84. U.B. Pal, D.E. Woolley, and G.B. Kenney: J. Mater., 2001(October), vol. 53, pp. 32-35.

85. S. Otsuka and Z. Kozuka: Metall. Trans. B, 1979, vol. 10, pp. $565-74$

86. S. Otsuka and Z. Kozuka: Metall. Trans. B, 1981, vol. 12 (3), pp. 501-07.

87. S. Otsuka, Z. Kozuka, and Y.A. Chang: Metall. Trans. B, 1984, vol. 15 (2), pp. 329-35.

88. B. Sears, T.J. Anderson, R. Narayanan, and A.L. Fripp: Metall. Trans. B, 1993, vol. 24 (1), pp. 91-100.

89. M. Iwase, M. Tanida, A. Mclean, and T. Mori: Metall. Trans. B, 1981, vol. 12 (3), pp. 517-24.

90. M. Sasabe, K. Goto, and M. Someno: Metall. Trans., 1970, vol. 1 (4), pp. 811-817.

91. M. Sasabe and K. Goto: Metall. Trans., 1974, vol. 5 (October), pp. 2225-33.

92. A.H. Caldwell and A. Allanore: J. Electroanal. Chem., 2020, vol. 861, p. 113709.

93. A.H. Caldwell: Doctoral thesis, Massachusetts Institute of Technology, 2020.

94. B.A. Rose, G.J. Davis, and H.JT. Ellingham: Discuss. Faraday Soc., 1948, vol. 4, pp. 154-62.

95. Y.K. Delimarskii and B. Markov: Electrochemistry of Fused Salts (translated by R.E. Wood), The Sigma Press, Washington DC, 1961.

96. R.C. Dorward: J. Appl. Electrochem., 1982, vol. 12 (5), pp. 54548.

97. T. Uda, T.H. Okabe, Y. Waseda, and K. Jacob: J. Alloys Compd., 1999, vol. 284 (1-2), pp. 282-88.

98. D.J. Ives and G. Janz: Reference Electrodes, Academic Press, New York, 1961

99. A.J. Bard and L.R. Faulkner: Electrochemical Methods: Fundamentals and Applications, 2nd ed., Wiley, New York City, 2000.

100. R.G. Compton and C.E. Banks: Understanding Voltammetry, Imperial College Press, London, 2011.

101. J. Diard, B. Le Gorrec, and C. Montella: Cinétique Electrochimique, Hermann, Paris, 1996.

102. K. Kawamura and T. Yokokawa: J. Electrochem. Soc., 1988, vol. 135 (6), pp. 1447-51.

103. A. Sasahira, K. Kawamura, M. Shimizu, N. Takada, M. Hongo, and T. Yokokawa: J. Electrochem. Soc., 1989, vol. 136 (7), pp. 1861-64.

104. F. Lantelme and E. Cherrat: J. Electrochem. Soc., 1988, vol. 244 (1-2), pp. 61-68.

105. F. Lantelme and E.H. Cherrat: J. Electrochem. Soc., 1991, vol. 297 (2), pp. 409-423.

106. G.R. Stafford and C.L. Hussey: in Advances in Electrochemical Science and Engineering, vol. 7, R.C. Alkire and D.M. Kolb, eds., Wiley-VCH Verlag GmbH, Weinheim, Germany, 2002, pp. 275-347.

107. T. Berzins and P. Delahay: J. Am. Chem. Soc., 1953, vol. 75 (3), pp. $555-59$.

108. A.M. Bond, N.W. Duffy, S.X. Guo, J. Zhang, and D. Elton: Anal. Chem., 2005, vol. 77, pp. 186A-195A. 
109. A. Bond, R. O'Halloran, I. Ruzic, and D. Smith: Anal. Chem., 1976, vol. 48 (6), pp. 872-83.

110. A.M. Bond, R.J. O'Halloran, I. Ruzic, and D.E. Smith: Anal. Chem., 1978, vol. 50 (2), pp. 216-23.

111. B.R. Nakanishi and A. Allanore: J. Electrochem. Soc., 2017, vol. 164 (13), pp. E460-E471.

112. B.R. Nakanishi and A. Allanore: J. Electrochem. Soc., 2019, vol. 166 (13), pp. E420-E428.
113. T. Abe, C. Kocer, M. Ode, H. Murakami, Y. Yamabe-Mitarai, K. Hashimoto, and H. Onodera: CALPHAD Comput. Coupling Phase Diag. Thermochem., 2008, vol. 32 (4), pp. 686-92.

Publisher's Note Springer Nature remains neutral with regard to jurisdictional claims in published maps and institutional affiliations. 